\title{
Aerosol size-dependent below-cloud scavenging by rain and snow in the ECHAM5-HAM
}

\author{
B. Croft ${ }^{1}$, U. Lohmann ${ }^{2}$, R. V. Martin ${ }^{1,3}$, P. Stier ${ }^{4}$, S. Wurzler ${ }^{5}$, J. Feichter ${ }^{6}$, R. Posselt ${ }^{7}$, and S. Ferrachat ${ }^{2}$ \\ ${ }^{1}$ Department of Physics and Atmospheric Science, Dalhousie University, Halifax, Canada \\ ${ }^{2}$ Institute of Atmospheric and Climate Science, ETH Zurich, Zurich, Switzerland \\ ${ }^{3}$ Harvard-Smithsonian Center for Astrophysics, Cambridge, USA \\ ${ }^{4}$ Atmospheric, Oceanic, and Planetary Physics, University of Oxford, Oxford, UK \\ ${ }^{5}$ Landesamt für Natur, Umwelt und Verbraucherschutz NRW (LANUV), Recklinghausen, Germany \\ ${ }^{6}$ Max Planck Institute for Meteorology, Hamburg, Germany \\ ${ }^{7}$ Federal Office of Meteorology and Climatology MeteoSwiss, Zurich, Switzerland
}

Received: 15 January 2009 - Published in Atmos. Chem. Phys. Discuss.: 25 March 2009

Revised: 25 Jun 2009 - Accepted: 1 July 2009 - Published: 17 July 2009

\begin{abstract}
Wet deposition processes are highly efficient in the removal of aerosols from the atmosphere, and thus strongly influence global aerosol concentrations, and clouds, and their respective radiative forcings. In this study, physically detailed size-dependent below-cloud scavenging parameterizations for rain and snow are implemented in the ECHAM5-HAM global aerosol-climate model. Previously, below-cloud scavenging by rain in the ECHAM5-HAM was simply a function of the aerosol mode, and then scaled by the rainfall rate. The below-cloud scavenging by snow was a function of the snowfall rate alone. The global mean aerosol optical depth, and sea salt burden are sensitive to the belowcloud scavenging coefficients, with reductions near to $15 \%$ when the more vigorous size-dependent below-cloud scavenging by rain and snow is implemented. The inclusion of a prognostic rain scheme significantly reduces the fractional importance of below-cloud scavenging since there is higher evaporation in the lower troposphere, increasing the global mean sea salt burden by almost $15 \%$. Thermophoretic effects are shown to produce increases in the global and annual mean number removal of Aitken size particles of near to $10 \%$, but very small increases (near 1\%) in the global mean belowcloud mass scavenging of carbonaceous and sulfate aerosols. Changes in the assumptions about the below-cloud scavenging by rain of particles with radius smaller than $10 \mathrm{~nm}$ do not cause any significant changes to the global and annual
\end{abstract}

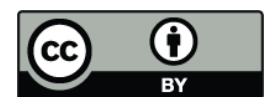

Correspondence to: B. Croft (croft@mathstat.dal.ca) mean aerosol mass or number burdens, despite a change in the below-cloud number removal rate for nucleation mode particles by near to five-fold. Annual and zonal mean nucleation mode number concentrations are enhanced by up to $30 \%$ in the lower troposphere with the more vigourous sizedependent below-cloud scavenging. Closer agreement with different observations is found when the more physically detailed below-cloud scavenging parameterization is employed in the ECHAM5-HAM model.

\section{Introduction}

Atmospheric aerosols significantly influence climate since they both reflect and absorb radiation (direct effects), and modify cloud properties (indirect radiative effects) (Twomey, 1991; Charlson et al., 1992). A general circulation model (GCM) must correctly quantify the global 3-dimensional distribution of the various aerosol species in order to accurately predict climate. Global aerosol distributions are strongly controlled by the rate of removal of aerosols from the atmosphere by wet scavenging processes (Rasch et al., 2000), and these processes are represented with a great diversity between models (Textor et al., 2006). To date, the belowcloud scavenging coefficients in the ECHAM5-HAM model have been a function of the aerosol mode (nucleation, Aitken, accumulation and coarse), and then scaled by the precipitation flux. However, in reality these scavenging coefficients can vary over one or two orders of magnitude within any given size mode (Greenfield, 1957; Wang et al., 1978). This

Published by Copernicus Publications on behalf of the European Geosciences Union. 
variability is due to a variety of physical processes, including an interplay of Brownian motion, and inertial impaction that produces a scavenging minimum for aerosols near $0.1 \mu \mathrm{m}$ in radius.

Previous modeling studies have implemented sizedependent below-cloud scavenging parameterizations for rain into regional and global models (Gong et al., 1997; Tost et al., 2006; Henzing et al., 2006). Tost et al. (2006) assumed a mean raindrop size as opposed to introducing a raindrop size distribution. Observational studies (Andronache, 2003; Andronache et al., 2006) have shown that below-cloud scavenging does depend on the aerosol and raindrop distribution. In this study, we include both the aerosol and raindrop distributions in the parameterization of the below-cloud scavenging coefficients, and investigate the deposition budgets for sulfate, black carbon, particulate organic matter, sea salt, and dust, and the 3-dimensional distributions of these aerosols in global simulations with the ECHAM5-HAM model. Since the ECHAM5-HAM model predicts the median radius of the log-normal distribution for each of seven aerosol modes, the detailed dependency of below-cloud scavenging on aerosol size can be included in the model.

Below-cloud scavenging by snow is more difficult to represent in models since more assumptions about the size and the shape of the crystals are required in order to estimate the collection efficiency of the snow. Previous global studies have typically used fixed mean below-cloud scavenging coefficients that are scaled by the snow flux (Stier et al., 2005; Tost et al., 2006). Gong et al. (1997) did apply an aerosol size-dependent below-cloud scavenging parameterization for snow following Slinn (1984) into a regional model for sea salt. This study uses a similar parameterization, following Slinn (1984) and Dick (1990) but extends the approach to global simulations of five aerosol species.

The goal of this study is to investigate the impacts of below-cloud scavenging parameterizations for both rain and snow on the vertical profiles of aerosol mass and number in the framework of a global model. For this study, we use the term below-cloud scavenging since the aerosol impaction scavenging by rain and snow is examined only below cloud base. We will consider the impacts of these parameterizations on global aerosol deposition, burdens, concentrations, and also on cloud properties, cloud radiative properties, and precipitation. Section 2 provides an overview of the ECHAM5-HAM model, and presents the collection efficiencies and below-cloud scavenging coefficients required for the aerosol size-dependent below-cloud scavenging parameterizations. Section 3 presents the results and discussion, comparing the various aerosol size-dependent below-cloud scavenging parameterizations in terms of their impacts on aerosol wet deposition, burdens, vertical profiles of aerosol mass and number concentrations, and clouds. Section 4 is the summary and conclusions.

\section{Model description}

ECHAM5 is a fifth generation atmospheric general circulation model (GCM) developed at the Max-Planck Institute for Meteorology (Roeckner et al., 2003), and evolved from the model of the European Centre for Medium Range Weather Forecasting (ECMWF). The model solves prognostic equations for vorticity, divergence, temperature and surface pressure using spheric harmonics with triangular truncation. Water vapor, cloud liquid water and ice are transported using a semi-Lagrangian scheme (Lin and Rood, 1996). Prognostic equations for cloud water and ice follow Lohmann et al. (2007). The model includes the cirrus scheme of Kärcher and Lohmann (2002). Convective clouds, and transport are based on the mass-flux scheme of Tiedtke (1989) with modifications following Nordeng (1994). The solar radiation scheme has 6 spectral bands (Cagnazzo et al., 2007) and the infrared has 16 spectral bands (Mlawer et al., 1997; Morcrette et al., 1998). The GCM is coupled to the Hamburg Aerosol Model (HAM), which is described in detail in Stier et al. (2005). The aerosols are represented by seven log-normal modes, 4 internally mixed/soluble modes (nucleation (NS), Aitken (KS), accumulation (AS), and coarse (CS)) and 3 insoluble modes (Aitken (KI), accumulation (AI), and coarse (CI)). The median radius for each mode is calculated from the aerosol mass and number distributions in each mode. Aerosol mass and number are transferred between the modes by the processes of sulfuric acid condensation, and also coagulation between aerosols. All results presented in this study are from a one year simulation, following a three months spin-up period, and are nudged towards the meteorological conditions of the year 2001. The nudging approach, combined with aerosol-radiation de-coupling, was chosen in order to have the same dust and sea salt emissions in all simulations. We chose the year 2001 since that was a neutral year for the El Nino Southern Oscillation. The natural emissions of sea salt, dust, and DMS from the oceans are calculated on-line, based on the meteorology of the model. Emissions for all other aerosol species are taken from the AEROCOM emission inventory, and are representative for the year 2000 (Dentener et al., 2006). The aerosol emissions and the removal processes of in-cloud scavenging, sedimentation, and dry deposition are described in detail in Stier et al. (2005).

\subsection{Below-cloud scavenging parameterizations}

\subsubsection{Current below-cloud scavenging parameteriza- tion}

The below-cloud scavenging parameterization in the control (CTL) simulation of the ECHAM5-HAM model follows Stier et al. (2005). The below-cloud scavenging coefficients are a function of the aerosol mode, and are scaled by the respective rain, or snow flux in each model layer. These coefficients are shown in Table 1, and for rain assume a fixed 
Table 1. Prescribed below-cloud scavenging coefficients $\left(\mathrm{m}^{2}\right.$ $\mathrm{kg}^{-1}$ ) as a function of aerosol mode, for the four internally mixed/soluble modes, nucleation (NS), Aitken (KS), accumulation (AS), coarse (CS), and the three insoluble modes, Aitken (KI), accumulation (AI), and coarse (CI).

\begin{tabular}{lll}
\hline & Rain & Snow \\
\hline NS & $5 \times 10^{-4}$ & $5 \times 10^{-3}$ \\
KS & $1 \times 10^{-4}$ & $5 \times 10^{-3}$ \\
AS & $1 \times 10^{-3}$ & $5 \times 10^{-3}$ \\
CS & $1 \times 10^{-1}$ & $5 \times 10^{-3}$ \\
KI & $1 \times 10^{-4}$ & $5 \times 10^{-3}$ \\
AI & $1 \times 10^{-3}$ & $5 \times 10^{-3}$ \\
CI & $1 \times 10^{-1}$ & $5 \times 10^{-3}$ \\
\hline
\end{tabular}

rain drop diameter of $4 \mathrm{~mm}$, and a lognormal aerosol distribution, following Fig. 20.15 in Seinfeld and Pandis (1998). The tracer tendency due to below-cloud scavenging is

$\frac{\overline{\Delta C_{i}}}{\Delta t}=C_{i}^{\mathrm{amb}} f^{\operatorname{precip}}\left(R_{i}^{r} F^{r}+R_{i}^{s} F^{s}\right)$

where $C_{i}^{\mathrm{amb}}$ is the ambient mixing ratio of the $i$ th tracer in the cloud-free air. $F^{r}$ and $F^{s}$ are the fluxes of rain and snow, respectively. $f^{\text {precip }}$ is the fraction of the grid box affected by precipitation. $R_{i}^{r}$ and $R_{i}^{s}$ are the below-cloud scavenging coefficients normalized by the precipitation flux for rain and snow, respectively.

\subsubsection{New below-cloud scavenging parameterization for rain}

The more physically detailed size-dependent below-cloud scavenging parameterization for rain used in all model simulations except CTL does not assume a fixed collector drop size, but instead assumes that the raindrops follow the distribution of Marshall and Palmer (1948),

$N\left(D_{p}\right)=n_{o} \exp \left(-\Lambda D_{p}\right)$

where

$\Lambda=4.1 R^{-0.21}$

and $n_{o}$ is $8 \times 10^{3} \mathrm{~m}^{-3} \mathrm{~mm}^{-1}$, and $D_{p}$ is the drop diameter in $\mathrm{mm}$, and $R$ is the rainfall rate in $\mathrm{mm} \mathrm{hr}^{-1}$.

The below-cloud scavenging coefficients as a function of aerosol size $\left(r_{p}\right)$ are given by

$\Lambda\left(r_{p}\right)=\int_{0}^{\infty} \pi R_{p}^{2} U_{t}\left(R_{p}\right) E\left(R_{p}, r_{p}\right) N\left(R_{p}\right) d R_{p}$

following Slinn (1984); Pruppacher and Klett (1998) and Seinfeld and Pandis (1998), where $E\left(R_{p}, r_{p}\right)$ is the collection efficiency as a function of the drop and aerosol radii, $R_{p}$ and $r_{p}$, respectively, and $U_{t}\left(R_{p}\right)$ is the drop's terminal velocity.
The collection efficiencies used in this study are compiled in a look-up table as a function of aerosol and collector drop size from the sources that are outlined in Table 2. The collection efficiency due to Brownian diffusion follows Young (1993) and is

$E_{\text {brownian }}=\frac{4 r_{b} D \overline{f_{a}}}{\left(r_{s}+r_{b}\right)^{2}\left|V_{\infty, b}-V_{\infty, s}\right|}$

where $D$ is the diffusion coefficient for small particles and $\overline{f_{a}}$ is the ventilation coefficient. The terminal velocities, $V_{\infty, b}$ and $V_{\infty, s}$ for the collector and aerosol particles, respectively, are dependent on particle size. For particles of radius, $r<10 \mu \mathrm{m}$, the terminal velocity is

$V_{\infty}=\left(1+\frac{1.26 \lambda_{a}}{r}\right) V_{s}$

where $V_{s}$ is the Stokes flow velocity and $\lambda_{a}$ is the mean free path of air molecules. For particles of radius $10 \leq r<500 \mu \mathrm{m}$,

$V_{\infty}=\frac{\eta_{a} N_{R e}}{2 \rho_{a} r}$

is the terminal velocity where $\eta_{a}$ and $\rho_{a}$ are the dynamic viscosity and density of air, respectively, and $N_{R e}$ is the Reynolds number (Beard and Pruppacher, 1969). Finally for the case where $r \geq 500 \mu \mathrm{m}$, the terminal velocity is given by the empirical approach for deformed drops based on Gunn and Kinzer (1949), Garner and Lihou (1965), and Beard (1976).

The modified Hall table, which is referred to in Table 2 is shown in Table 3. These values are from Hall (1980) except for collector drop radii $\leq 30 \mu \mathrm{m}$ new efficiencies were generated by averaging from the values in Lin and Lee (1975), Schlamp et al. (1976) and Klett and Davis (1973). The final assumption is that all collisions result in collection. Thus, the coagulation efficiency is assumed to be unity.

Examples of the collection efficiencies for certain collector partner sizes are shown in Fig. 1. Aerosols with radii less than about $0.1 \mu \mathrm{m}$ are more efficiently collected due to their Brownian motion, and larger aerosols are more efficiently collected due to their inertia. Thus, there is a minimum collection efficiency for particle radius near $0.1 \mu \mathrm{m}$, as first presented by Greenfield (1957), which is often called the Greenfield gap. Aerosols in this size range are most readily swept around the falling drop. Equations to parameterize these collection efficiencies do exist (Slinn, 1984; Jung and Lee, 1998). These equations parameterize the collection efficiency due to the processes of Brownian diffusion, interception, and inertial impaction. One advantage of our approach is that the code can be readily modified to introduce tables that include the effects of thermophoresis, as has been done in this study, or additionally turbulence or electric charge, and the approach can be more readily extended over a wider range of size of collision partners, such as for in-cloud impaction scavenging. 
Table 2. Collision efficiencies as a function of the radii of the bigger and smaller collision partners, $r_{b}$ and $r_{s}$, respectively.

\begin{tabular}{|c|c|c|}
\hline$r_{b}(\mu \mathrm{m})$ & $r_{s}(\mu \mathrm{m})$ & collision efficiency \\
\hline$r_{b}>300$ & $r_{s}>10$ & 1. \\
\hline $300 \geq r_{b}>10$ & $r_{S}>10$ & modified tables from Hall (1980) (see Table 3) and grid square method with bilinear interpolation \\
\hline$r_{b}>300$ & $10 \geq r_{s}>0.2$ & $\begin{array}{l}\text { values interpolated between Brownian diffusion and Wang et al. (1978) data using logarithmic inter- } \\
\text { polation }\end{array}$ \\
\hline $300 \geq r_{b}>42$ & $10 \geq r_{s}>0.2$ & values from Wang et al. (1978), Fig. 4, curves 4-D and grid square method with bilinear interpolation \\
\hline $42 \geq r_{b}>10$ & $10 \geq r_{s}>0.5$ & $\begin{array}{l}\text { values interpolated between Brownian diffusion, modified Hall table and Wang et al. (1978) data } \\
\text { using grid square method with bilinear interpolation }\end{array}$ \\
\hline $42 \geq r_{b}>10$ & $0.5 \geq r_{s}>0.2$ & Brownian diffusion \\
\hline$r_{b} \leq 10$ & $10 \geq r_{s}>0.5$ & $\begin{array}{l}\text { values interpolated between Brownian diffusion, modified Hall table and Wang et al. (1978) data } \\
\text { using logarithmic interpolation }\end{array}$ \\
\hline$r_{b} \leq 10$ & $0.5 \geq r_{s}>0.2$ & Brownian diffusion \\
\hline all values of $r_{b}$ & $r_{s} \leq 0.2$ & Brownian diffusion \\
\hline
\end{tabular}

Table 3. Collision efficiencies from Hall (1980) and modified for drop radii $\leq 30 \mu \mathrm{m}$. The bigger and smaller collision partners are $r_{b}$ and $r_{s}$, respectively.

\begin{tabular}{llllllllllll}
\hline$r_{b}(\mu \mathrm{m})$ & 300 & 200 & 150 & 100 & 70 & 60 & 50 & 40 & 30 & 20 & 10 \\
\hline$r_{s} / r_{b}$ & & & & & & & & & & & \\
\hline 0.05 & 0.97 & 0.87 & 0.77 & 0.5 & 0.18 & 0.05 & 0.005 & 0.001 & 0.0001 & 0.0001 & 0.0001 \\
0.10 & 1.0 & 0.96 & 0.93 & 0.79 & 0.56 & 0.43 & 0.40 & 0.07 & 0.002 & 0.0001 & 0.0001 \\
0.15 & 1.0 & 0.98 & 0.97 & 0.91 & 0.80 & 0.64 & 0.60 & 0.28 & 0.02 & 0.005 & 0.0001 \\
0.20 & 1.0 & 1.0 & 0.97 & 0.95 & 0.88 & 0.77 & 0.70 & 0.50 & 0.04 & 0.015 & 0.013 \\
0.25 & 1.0 & 1.0 & 1.0 & 0.95 & 0.90 & 0.84 & 0.78 & 0.62 & 0.085 & 0.023 & 0.016 \\
0.30 & 1.0 & 1.0 & 1.0 & 1.0 & 0.91 & 0.87 & 0.83 & 0.68 & 0.17 & 0.032 & 0.02 \\
0.35 & 1.0 & 1.0 & 1.0 & 1.0 & 0.94 & 0.89 & 0.86 & 0.74 & 0.27 & 0.043 & 0.024 \\
0.40 & 1.0 & 1.0 & 1.0 & 1.0 & 0.95 & 0.90 & 0.88 & 0.78 & 0.40 & 0.054 & 0.028 \\
0.45 & 1.0 & 1.0 & 1.0 & 1.0 & 0.96 & 0.91 & 0.90 & 0.80 & 0.50 & 0.065 & 0.031 \\
0.50 & 1.0 & 1.0 & 1.0 & 1.0 & 0.97 & 0.91 & 0.90 & 0.80 & 0.53 & 0.075 & 0.034 \\
0.55 & 1.0 & 1.0 & 1.0 & 1.0 & 0.98 & 0.91 & 0.90 & 0.80 & 0.54 & 0.081 & 0.035 \\
0.60 & 1.0 & 1.0 & 1.0 & 1.0 & 0.98 & 0.91 & 0.90 & 0.78 & 0.54 & 0.084 & 0.036 \\
0.65 & 1.0 & 1.0 & 1.0 & 1.0 & 0.98 & 0.91 & 0.89 & 0.77 & 0.54 & 0.082 & 0.037 \\
0.70 & 1.0 & 1.0 & 1.0 & 1.0 & 0.99 & 0.92 & 0.88 & 0.76 & 0.53 & 0.078 & 0.037 \\
0.75 & 1.0 & 1.0 & 1.0 & 1.0 & 1.0 & 0.93 & 0.88 & 0.77 & 0.51 & 0.07 & 0.037 \\
0.80 & 1.0 & 1.0 & 1.0 & 1.0 & 1.05 & 0.95 & 0.89 & 0.77 & 0.48 & 0.06 & 0.037 \\
0.85 & 1.0 & 1.0 & 1.0 & 1.0 & 1.10 & 1.0 & 0.92 & 0.78 & 0.46 & 0.05 & 0.036 \\
0.90 & 1.0 & 1.0 & 1.0 & 1.0 & 1.3 & 1.03 & 1.01 & 0.79 & 0.43 & 0.042 & 0.034 \\
0.95 & 1.0 & 1.0 & 1.0 & 1.0 & 2.0 & 1.7 & 1.3 & 0.95 & 0.44 & 0.035 & 0.032 \\
1.00 & 1.0 & 1.0 & 1.0 & 1.0 & 4.0 & 3.0 & 2.3 & 1.4 & 0.52 & 0.027 & 0.027 \\
\hline & & & & & & & & & & &
\end{tabular}

To obtain the mean below-cloud scavenging coefficients for the mass distributions as a function of aerosol median diameter, $\Lambda_{m}\left(r_{p m}\right)$, a second integration over the aerosol size distribution $n\left(r_{p}\right)$ is done,

$\Lambda_{m}\left(r_{p m}\right)=\frac{\int_{0}^{\infty} \Lambda\left(r_{p}\right) r_{p}^{3} n\left(r_{p}\right) d r_{p}}{\int_{0}^{\infty} r_{p}^{3} n\left(r_{p}\right) d r_{p}}$.

Similarly, the mean below-cloud scavenging coefficients for the number distributions are,

$\Lambda_{n}\left(r_{p m}\right)=\frac{\int_{0}^{\infty} \Lambda\left(r_{p}\right) n\left(r_{p}\right) d r_{p}}{\int_{0}^{\infty} n\left(r_{p}\right) d r_{p}}$.
The resulting mass and number distribution scavenging coefficients are shown in Fig. 1. These coefficients have a minimum for aerosol sizes near $0.1 \mu \mathrm{m}$ due to the collection efficiency minimum. Scavenging coefficients are higher for higher rainfall rates. A look-up table of these scavenging coefficients as a function of aerosol size and rainfall flux is used in the model. These coefficients are applied as $R_{i}^{r} F^{r}$ in Eq. (1).

Figure 2 shows how the assumption of an exponential raindrop distribution as opposed to assuming all the raindrops are either $0.4 \mathrm{~mm}$ or $4.0 \mathrm{~mm}$ can give differences in the 

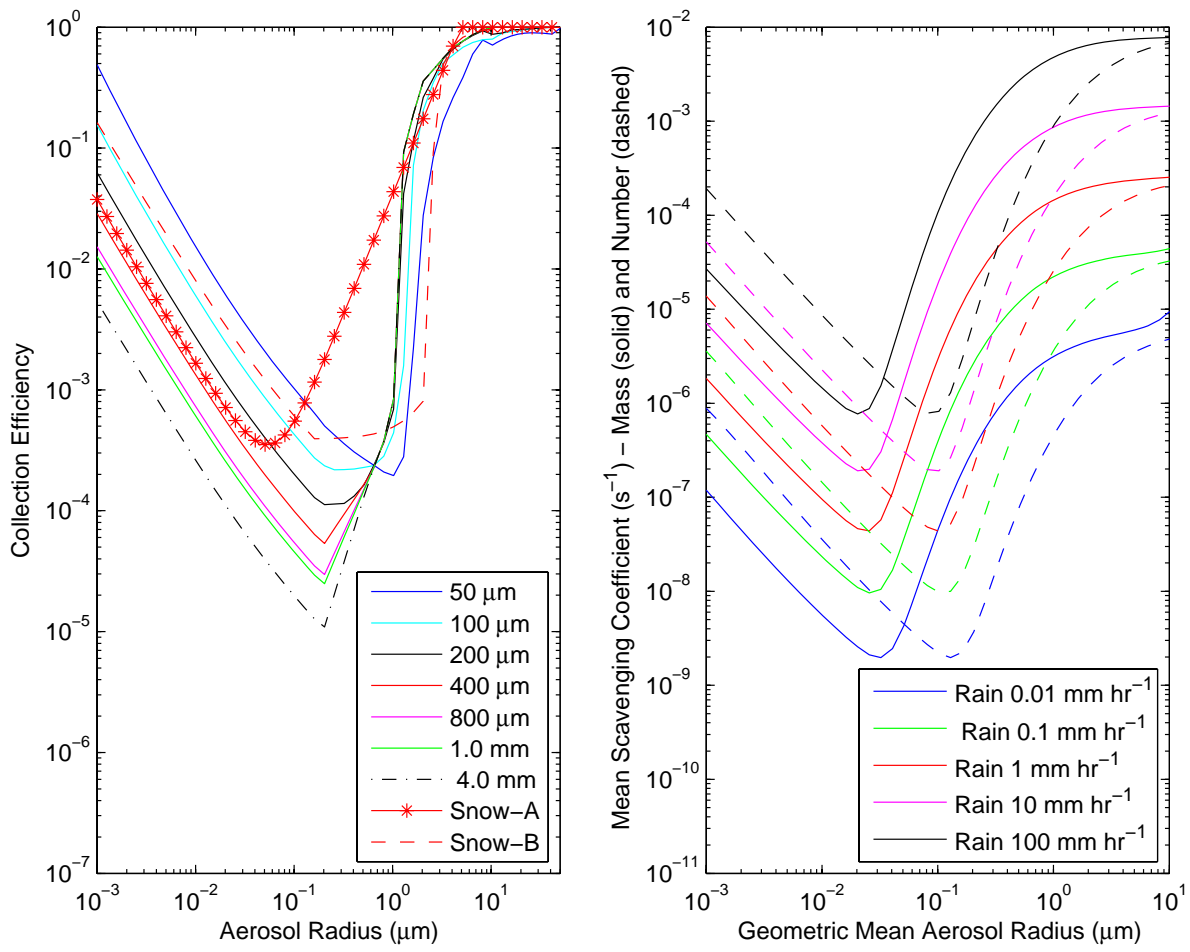

Fig. 1. Collision efficiency for raindrop-aerosol collisions as a function of aerosol radius and collector rain drop size is shown on the left panel. Also on the left is the snow-aerosol collision efficiency (Snow A: Dick, 1990; Snow B: Slinn, 1984). Coagulation efficiency is assumed to be unity. Mean mass (solid lines) and number (dashed lines) below-cloud scavenging coefficients ( $\mathrm{s}^{-1}$ ) as a function of aerosol modal radius and rainfall rate are shown on right panel.

below-cloud scavenging coefficients of more than an order of magnitude. The differences in the scavenging coefficients, assuming various exponential distributions for drizzle, thunderstorm and the standard Marshall-Palmer distribution, are not as great as the difference in the coefficients if all the raindrops are assumed to be one size. The exponential raindrop distributions generally give coefficients that are between the coefficients for unimodal 0.4 and $4.0 \mathrm{~mm}$ raindrops, except for the scavenging of ultra-fine particles, which is greatest in the case of drizzle. The exponential distributions are from Joss and Waldvogel (1969). The equations for the scavenging coefficients assuming unimodal raindrops are given in Seinfeld and Pandis (1998). For mass scavenging of aerosols with radii over $50 \mathrm{~nm}$, all coefficients shown in Fig. 2 exceed those used by Stier et al. (2005) by up to 2 orders of magnitude.

Figure 3 shows how these scavenging coefficients are influenced by lower relative humidity. Based on the collection efficiencies of Wang et al. (1978), the mean mass and number scavenging coefficients have been re-calculated. Decreasing relative humidity increases scavenging in the Greenfield gap since the evaporating raindrops are cooler at the surface, and this sets up a thermal gradient that induces motion of the aerosols towards the cooler raindrop surface. Away from the Greenfield gap, other physical processes such as Brownian motion and inertial impaction dominate the collection, and so the influence of relative humidity is less pronounced. This is particularly evident at lower rainfall rates.

Andronache et al. (2006) found that observed scavenging coefficients for ultrafine particles exceeded model calculations for below-cloud scavenging based on Brownian motion, interception, and typical phoretic and charge effects. Here, we present two sensitivity studies for the below-cloud scavenging of particles with radius smaller than $10 \mathrm{~nm}$, and investigate the impact on global aerosol concentrations and deposition. Figure 4 shows the scavenging coefficients for the extreme assumption that the collection efficiency is zero for ultra-fine particles that are smaller than $10 \mathrm{~nm}$ in radius. These coefficients are used in the sensitivity study BCS2ULOW. As an additional sensitivity test, we assume that the collection of particles smaller than $10 \mathrm{~nm}$ radius can be described by the mass transfer coefficient, $K_{c}$, for the transfer of a gaseous molecule to a falling rain drop (Seinfeld and Pandis, 1998).

$K_{c}=\frac{D_{g}}{2 R_{p}}\left(2+0.6\left(\frac{2 R_{p} U_{t}}{v}\right)^{1 / 2}\left(\frac{v}{D_{g}}\right)^{1 / 3}\right)$

where $D_{g}$ is the diffusivity coefficient for the gas in air $\left(\mathrm{cm}^{2} \mathrm{~s}^{-1}\right), v$ is the kinematic viscosity $\left(\mathrm{cm}^{2} \mathrm{~s}^{-1}\right), U_{t}$ is the 

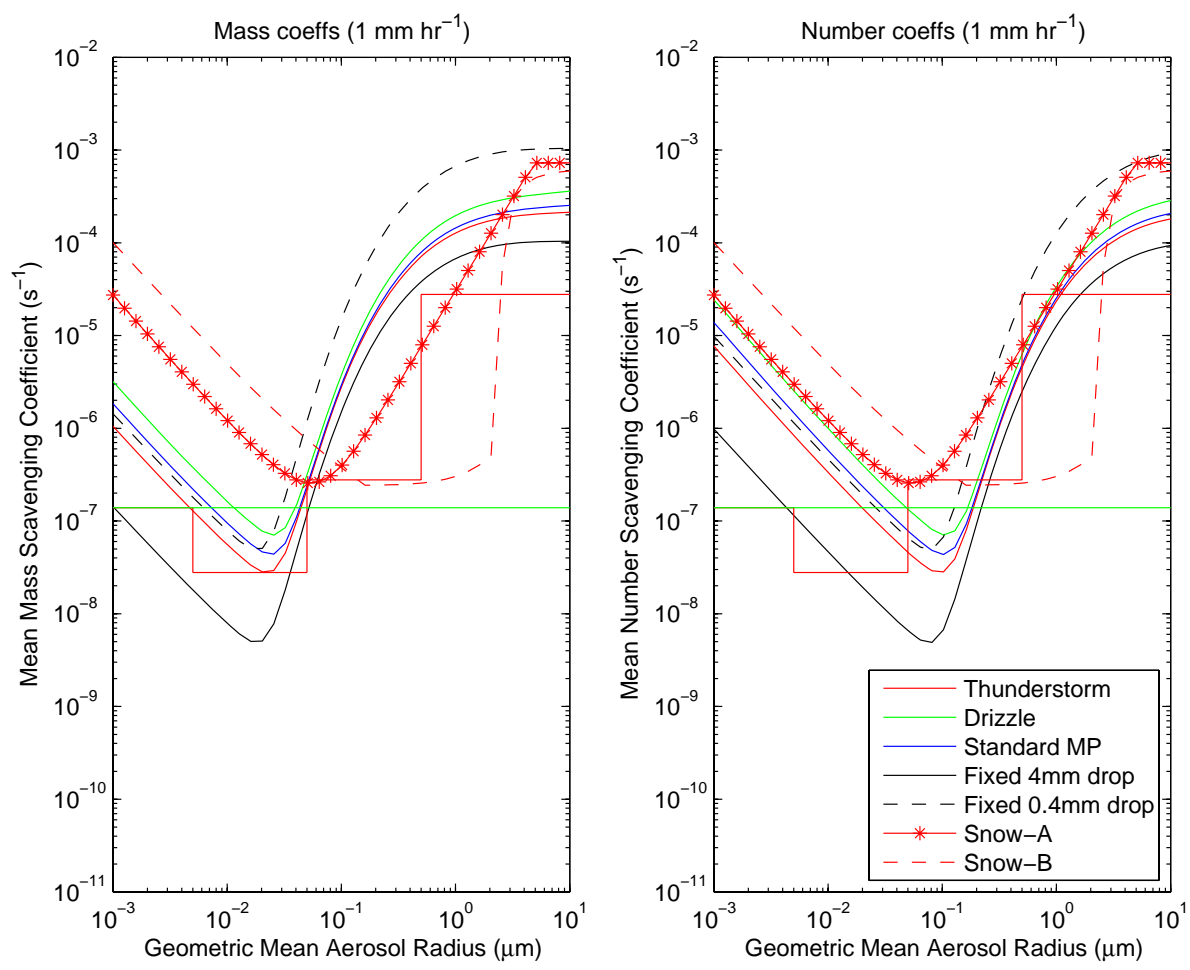

Fig. 2. Mean below-cloud scavenging coefficients for a precipitation rate of $1 \mathrm{~mm} \mathrm{hr}^{-1}$, assuming exponential distributions for thunderstorm, drizzle, and the standard Marshall Palmer. Also, assuming unimodal distributions for raindrop radii of $4 \mathrm{~mm}$ and $0.4 \mathrm{~mm}$, and a fixed snow crystal radius. Mass scavenging coefficients are on left panel and number scavenging coefficients are on the right panel. Red and green steps: modal coefficients of Stier et al. (2005) for rain and snow, respectively.

terminal velocity of the falling rain drop, and $R_{p}$ is the rain drop radius. We assume that the particles behave as the gas water vapor. The mass transfer coefficients are used in place of $U_{t}\left(R_{p}\right) E\left(R_{p}, r_{p}\right)$ in Eq. (4), and the mean mass and number scavenging coefficients are found following Eqs. (8) and (9). For aerosol particles near to $10 \mathrm{~nm}$ in radius, the mean mass and number scavenging coefficients are increased by near to two orders to magnitude for this assumption. These coefficients are used in the sensitivity simulation BCS2UHIGH.

\subsubsection{New below-cloud scavenging parameterization for snow}

For the below-cloud scavenging by snow, the CTL simulation of the ECHAM5-HAM follows Eq. (1) and the value of $R_{i}^{s}$ is fixed at $0.005 \mathrm{~m}^{2} \mathrm{~kg}^{-1}$ for all aerosol modes. To make the below-cloud scavenging by snow depend on the aerosol size, a size-dependent collection efficiency for snow is required. Following Dick (1990) the collection efficiency is

$E=\frac{m U_{t}}{6 \pi r \eta R}+4 P e^{-1}\left(1+0.4 R e^{1 / 6} P e^{1 / 3}\right)$

where $m$ is the aerosol particle mass, $U_{t}$ is the terminal velocity of the snow crystals, $r$ is the radius of the aerosol par- ticles, $\eta$ is the absolute viscosity of air, $R$ is the radius of the snow crystals, $R e$ is the Reynold's number and $P e$ is the Peclet number. Following Dick (1990), we assume that all snow crystals are $30 \mu \mathrm{g}$ in mass and have a radius of $0.5 \mathrm{~mm}$ and fall at a terminal velocity of $80 \mathrm{~cm} \mathrm{~s}^{-1}$. The Reynold's number is

$R e=\frac{\rho_{a} R U_{t}}{\eta}$

where $\rho_{a}$ is the air density. The Peclet number is

$P e=\frac{2 R U_{t}}{D}$

where $D$ is the aerosol diffusivity. Again following Dick (1990), the scavenging coefficient normalized by the precipitation flux is the collection efficiency multiplied by the crosssectional area of a snow crystal divided by the snow crystal mass $M$,

$R^{s}(r)=\frac{\pi R^{2}}{M} E$

As an alternative, the collection efficiency equation of Slinn (1984) may be used. The collection efficiency for snow is given by,

$E(r)=\left(\frac{1}{S c}\right)^{\alpha}+\left(1-\exp \left(-\left(1+R e_{\lambda}^{1 / 2}\right)\right) \frac{r^{2}}{\lambda^{2}}\right)+\left(\frac{S t-S_{*}}{S t-S_{*}+\frac{2}{3}}\right)^{3 / 2}$ 

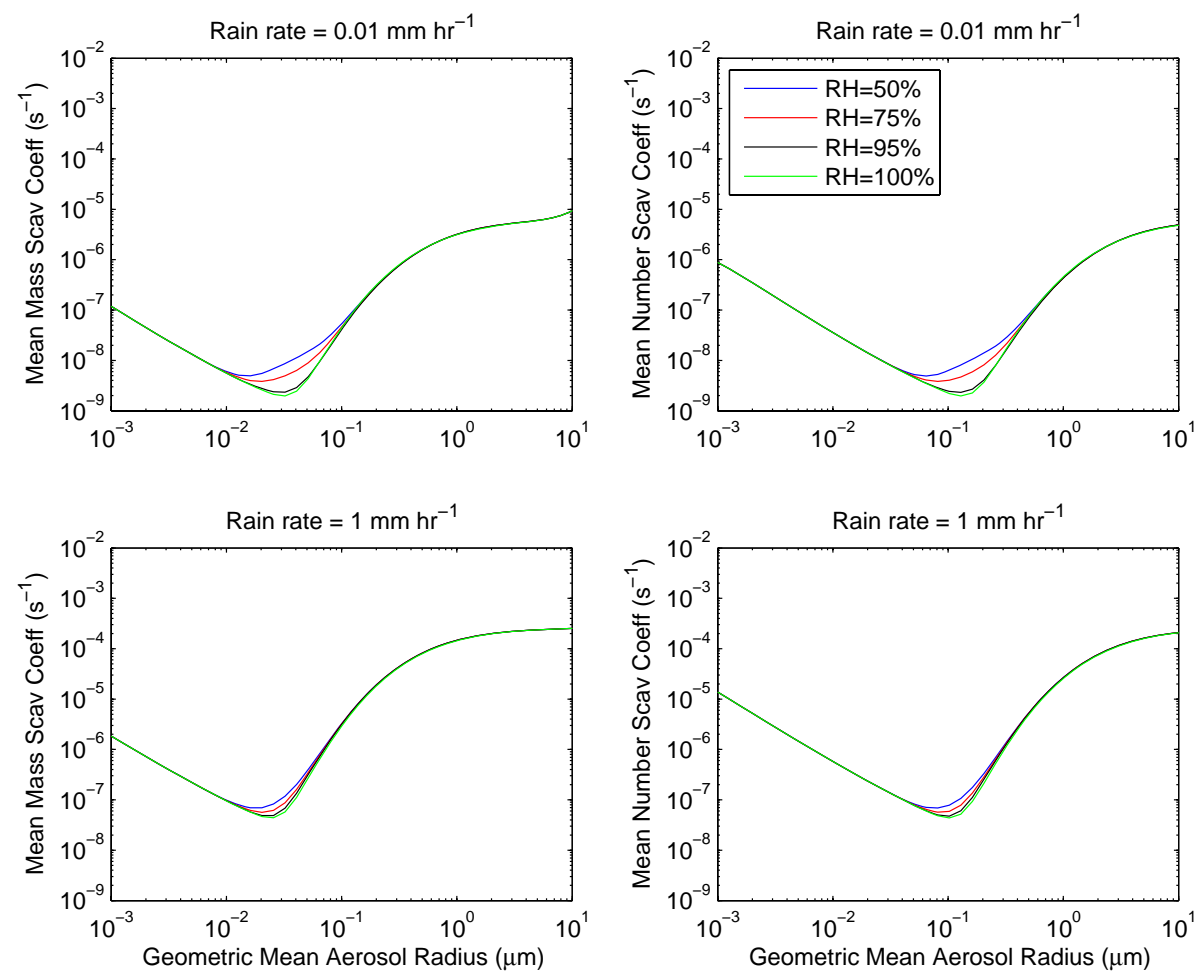

Fig. 3. Mean below-cloud mass and number scavenging coefficients for rain with thermophoretic effects included for relative humidities of $50 \%, 75 \%, 95 \%$ and $100 \%$, and for rainfall rates of 0.01 and $1 \mathrm{~mm} \mathrm{hr}^{-1}$.

where $S c$ is the Schmidt number, $R e$ is the Reynold's number and $S t$ is the Stokes number and $r$ is the aerosol size. The parameter $S_{*}$ is given as

$S_{*}=\frac{12 / 10+(1 / 12) \ln (1+R e)}{1+\ln (1+R e)}$

where $R e$ is the Reynold's number. The parameters $\alpha$ and $\lambda$ depend on the type of snow crystals. For this study, the crystals were assumed to be rimed crystals, and thus $\alpha$ and $\lambda$ were fixed at $100 \mu \mathrm{m}$ and $2 / 3$, respectively. Following Slinn (1984), the scavenging coefficient as a function of aerosol size $r$, and normalized by the snow fall rate is given by,

$R^{s}(r)=\frac{\gamma E(r)}{D_{m}}$

where $D_{m}$ is a characteristic length of $2.7 \times 10^{-3} \mathrm{~cm}$ for rimed particles and $\gamma$ is a fixed parameter of order unity $(0.6)$. Figure 1 shows the collection efficiencies for snow from both Dick (1990) (Snow-A) and Slinn (1984) (Snow-B). Figure 2 shows how these scavenging coefficients for snow compare to the fixed coefficient for a precipitation rate of $1 \mathrm{~mm} \mathrm{hr}^{-1}$, which is shown as the horizontal green line. The conversion from precipitation flux was made by assuming the snow density was 0.1 of the water density. These size dependent scavenging coefficients for snow are higher than the coefficients used in the CTL simulation by a few orders of magni- tude, particularly for the nucleation and coarse modes. The scavenging minimum is at a different radius and has a different width for the two parameterizations. This is due to differences in the assumptions about the morphology of the snow particles, similar to that presented by Miller and Wang (1991) and Feng (2009). This study has implemented the coefficients of Slinn (1984). The parameterization of belowcloud scavenging by snow is difficult since there are many assumptions to be made about the snow crystal properties. While our assumptions are reasonable, there remains considerable uncertainty since the variability in the size and shape of the snow crystals is neglected.

All below-cloud scavenging parameterizations require a representation of the precipitation fraction. The stratiform precipitating fraction is found starting from the top layer of the model and descending the vertical column. The precipitation fraction is set to the cloud fraction in the first precipitating layer. Thereafter, the precipitating fraction remains the same in subsequent layers until the amount of precipitation formed in any layer exceeds the amount of precipitation formed in the overlying layers. In the latter case, the precipitation fraction is set to the cloud fraction of that layer and so forth down the vertical column. The precipitation fraction is further adjusted if the cloud fraction exceeds the precipitating fraction from the overlying layer, but 

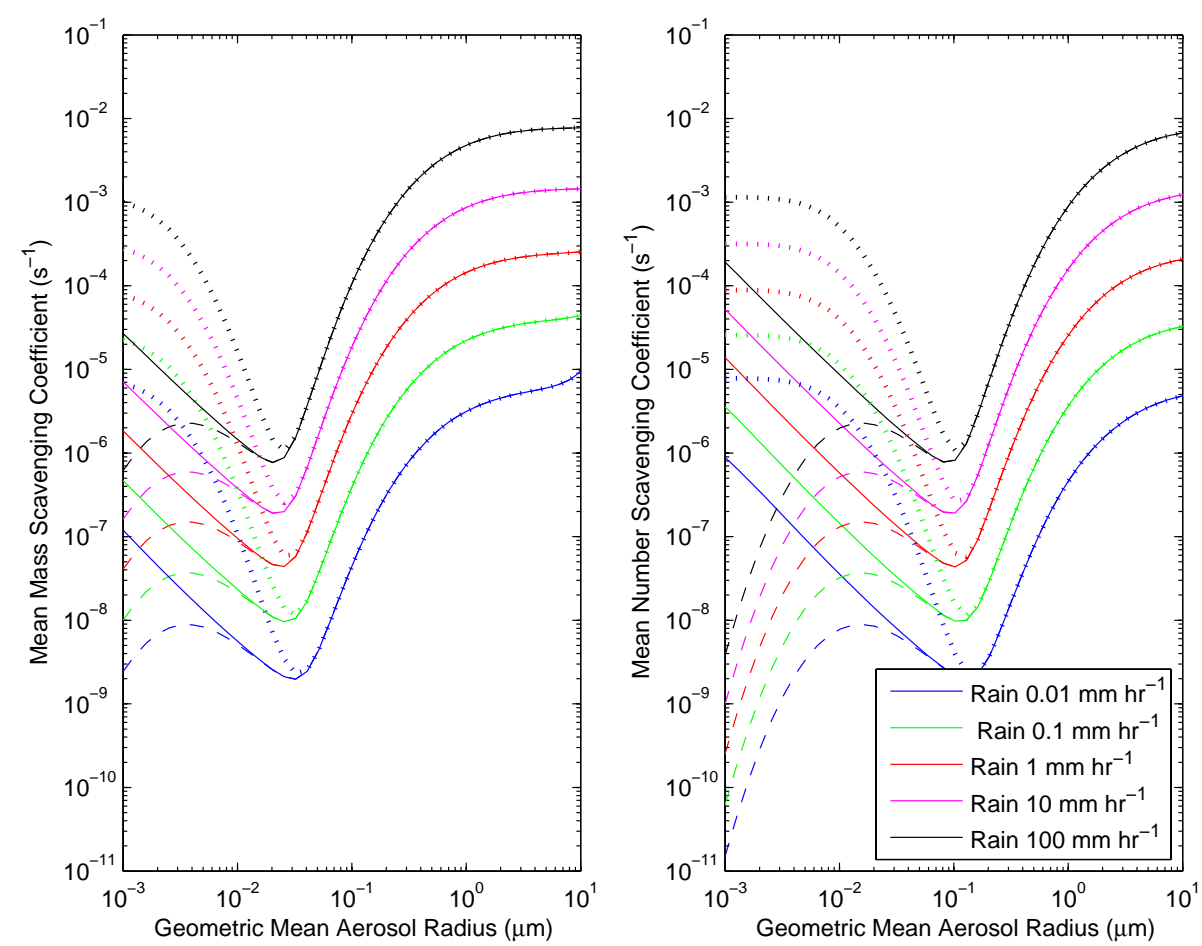

Fig. 4. Mean below-cloud mass and number scavenging coefficients for rain, assuming the standard Marshall-Palmer raindrop distribution for five rainfall rates, and for three assumptions about the collection of particles with radius smaller than $10 \mathrm{~nm}$ : collection due to Brownian motion (solid lines), zero collection efficiency (dashed lines), and collection behavior similar to an irreversibly soluble gas (dotted lines).

the precipitation generated in that layer does not exceed that from overlying layers. In this case, the new precipitation fraction is the weighted sum of the precipitation fraction and precipitation generated from the over-lying layers, and the cloud fraction and precipitation generated in the given layer. In all simulations except BCS2-CPF, the convective precipitation fraction in the $k$ th model layer is,

$P F_{\text {conv }}(k)=\frac{M F_{\text {up }}}{v_{\text {up }}(k) \rho_{\text {air }}(k)}$

where $M F_{\text {up }}$ is the updraft mass flux, $v_{\text {up }}(k)$ is a prescribed updraft velocity $\left(2 \mathrm{~m} \mathrm{~s}^{-1}\right)$, and $\rho_{\text {air }}$ is the air density. Since below-cloud scavenging is parameterized to occur only in completely clear layers, this might under-estimate the scavenging because $P F_{\text {conv }}(k)$ is likely to be lower in cloudfree layers than in cloudy layers. Thus, in the sensitivity simulation, BCS2-CPF, the convective precipitating fraction is found using a maximum overlap assumption, and a precipitation-based weighting of the precipitating fractions from overlying layers. That is,

$P F_{\text {conv }}^{\text {new }}(k)=\frac{\sum_{z=\text { ktop }}^{k} P F_{\text {conv }}(k) \cdot P_{\text {form }}(k)}{\sum_{z=\text { ktop }}^{k} P_{\text {form }}(k)}$

where $P_{\text {form }}$ is the precipitation formed in the $k$ th layer.

\section{Results and discussion}

\subsection{Mass deposition budgets}

Table 4 summarizes the model simulations. Figures 5 and 6 show the geographic distribution of the annual mean mass wet deposition of sulfate, black carbon (BC), particulate organic matter (POM), sea salt (SS) and dust (DU) for the simulation BCS2, which has size-dependent below-cloud scavenging for both rain and snow. These figures also compare the wet deposition between the BCS2 and CTL simulations. Modification to the below-cloud scavenging parameterization is shown to produce the greatest changes in the sea salt and dust wet deposition. Wet deposition of these aerosols is increased close to source regions for the BCS2 simulation. Henzing et al. (2006) also showed that below-cloud scavenging is an important sink for sea salt particles, near to $12 \%$ of global removal, and should be included in a size-resolved parameterizations, such as was also done by Gong et al. (1997).

In terms of mass, the wet deposition of the carbonaceous aerosols and sulfate is shown to be least influenced by the below-cloud scavenging parameterization on a global scale, but there are regional changes. Unlike sea salt and dust, wet deposition is not significantly increased at the major source regions. However, in the zonal band near $20^{\circ} \mathrm{N}$ there is increased wet deposition. This latter feature is associated with 


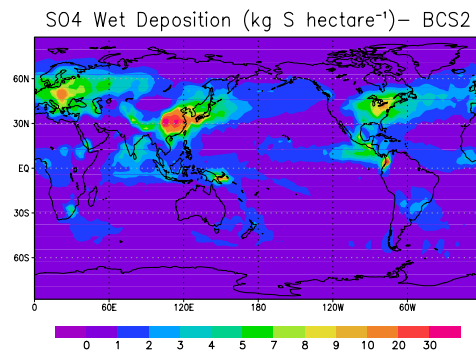

BC Wet Deposition (kg C hectare ${ }^{-1}$ ) - BCS2

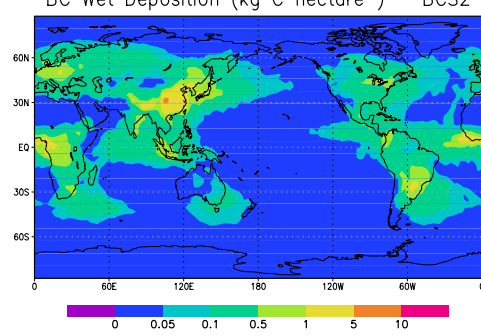

POM Wet Deposition (kg POM hectare ${ }^{-1}$ ) - BCS2

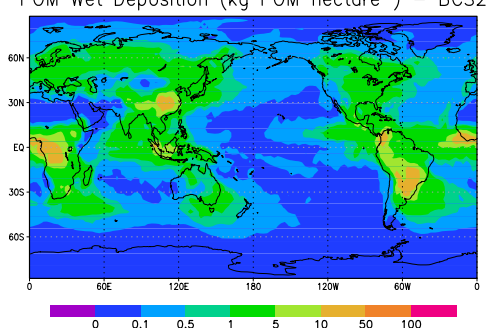

\% Change SO4 WD (BCS2 vs. CTL)

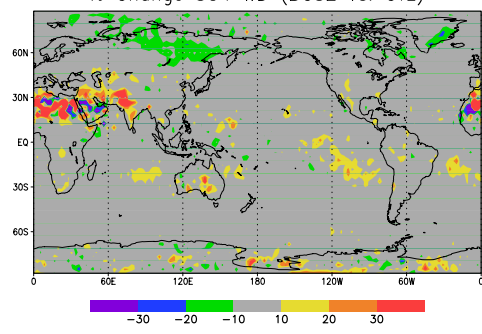

\% Change BC WD (BCS2 vs. CTL)

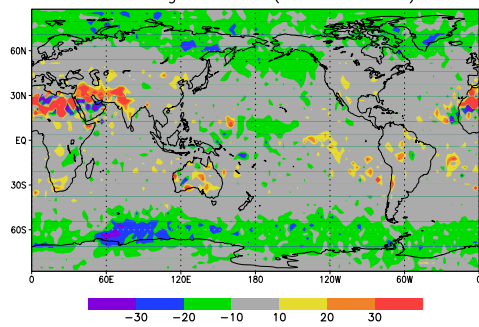

\% Change POM WD (BCS2 vs. CTL)

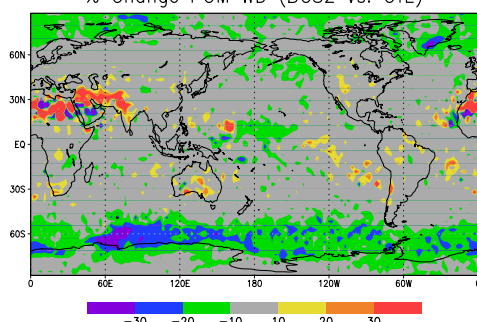

Fig. 5. The geographic distribution of annual mean wet deposition of sulfate, black carbon and particulate organic matter for the BCS2 simulation is shown on the left panels. The percent change in the wet deposition relative to the control simulation ((BCS2-CTL)/CTL) is shown on the right panels.

an aerosol-precipitation feedback triggered by the belowcloud scavenging parameterizations and will be discussed further in the following sub-sections. Additionally, there is reduced wet deposition of dust and carbonaceous aerosols in the latitude band near $60^{\circ} \mathrm{S}$, which is indicative of reduced poleward transport of these aerosols in response to increased wet deposition somewhat closer to their sources. To better understand whether these changes in wet deposition are due to the revised parameterizations, or due to differences in the precipitation rates, the change in total precipitation rates between the simulations BCS2 and CTL is shown in Fig. 6. Over the southern oceans, the precipitation is not changed by more than $5 \%$, and so increases to the sea salt deposition here are primarly due to the new parameterizations. However, over regions of Northern Africa, and small, local regions in the tropics, there are changes to the precipitation that do contribute to the differences in the wet deposition.

Tables 5-9 present the annual and global mean mass deposition budgets for the various simulations. The annual and global mean mass removal by below-cloud scavenging is shown to be highly sensitive to the choice of belowcloud scavenging coefficients, with an increase of between one and two orders of magnitude for the BCS2 simulation as compared to the CTL simulation for the various aerosol species. The mass deposition budgets for sea salt and dust are controlled by the scavenging of the coarse mode, whereas the sulfate, black carbon, and particulate organic matter mass deposition budgets are dominated by the accumulation mode scavenging. Figure 2 shows that the CTL simulation uses much lower coefficients for accumulation and coarse mode mass scavenging than the other simulations with sizedependent scavenging. As a result, this low mass removal in the CTL simulation is expected. Tables 5-9 show that the mass removal by below-cloud scavenging is highly sensitive to the assumptions about the raindrop distribution with differences up to $60 \%$ between the BCS2, BCS2-M0.4 and BCS2M4.0 simulations. Assuming all the raindrops are $0.4 \mathrm{~mm}$ in size gives the highest removal of mass by below-cloud scavenging. These effects occur for all aerosol species. Increases in the mass removal by below-cloud scavenging are associated with decreases in the mass removal by in-cloud scavenging. This is expected since the greater aerosol removal below cloud base allows less aerosol to be available for transport upward to the altitudes where in-cloud scavenging occurs. 

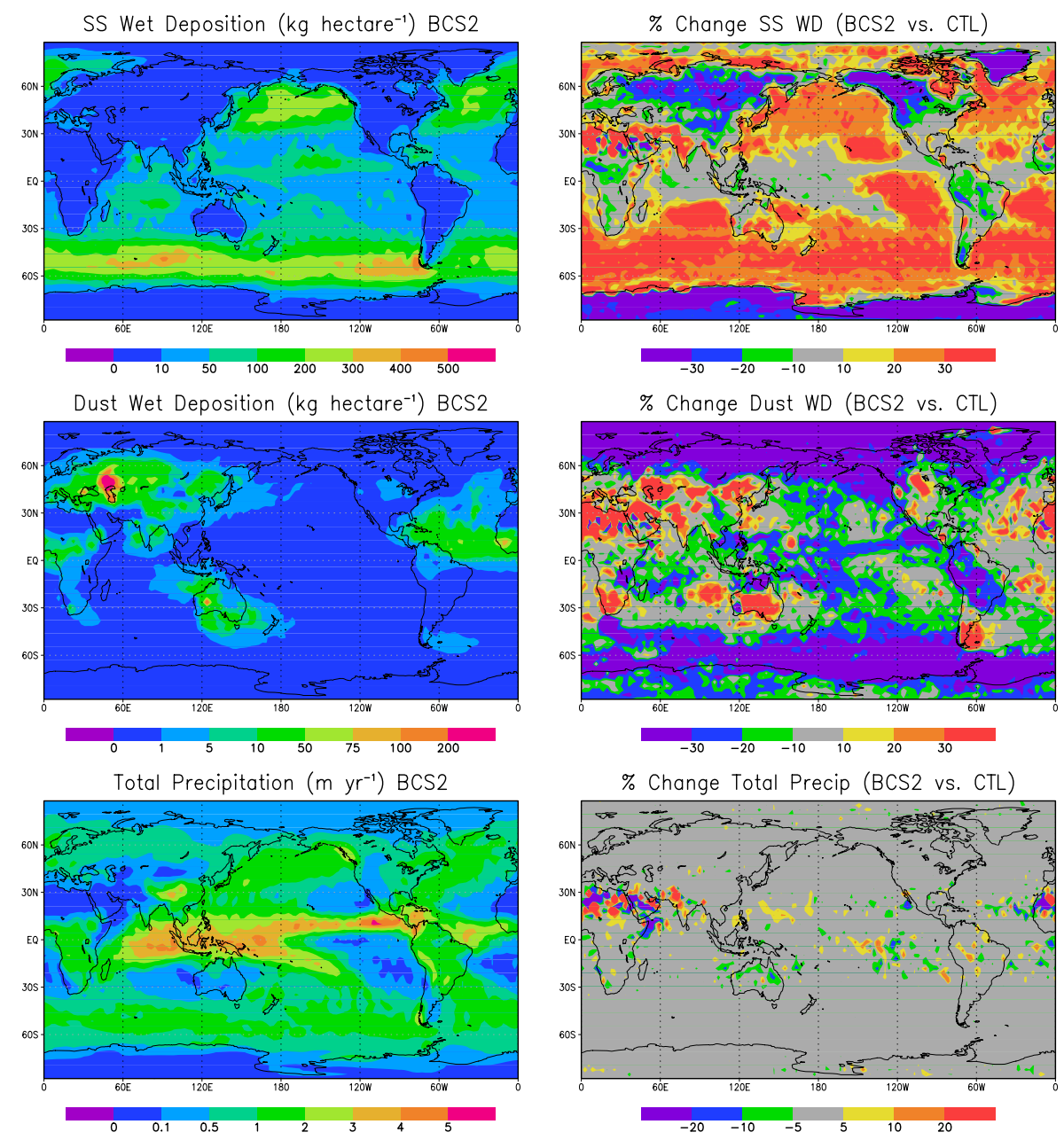

Fig. 6. The geographic distribution of annual mean wet deposition of sea salt and dust and total precipitation for the BCS2 simulation is shown on the left panels. The percent change in the wet deposition and total precipitation relative to the control simulation ((BCS2CTL)/CTL) is shown on the right panels.

Sedimentation and dry mass deposition rates are also reduced in response to the lower aerosol concentrations. For sea salt, the global and annual mean fraction of mass removal by below-cloud scavenging for the simulation BCS2 (23\%) is higher than that reported by Henzing et al. (2006) (12\%) using the global chemistry transport model TM4, and considerably higher than for the CTL simulation (3\%).

Table 10 shows the relative contributions of both stratiform and convective rain and snow to the total mass removal by below-cloud scavenging for all 5 aerosol species. Stratiform rain accounts for the majority of the below-cloud scavenging, near to $60 \%$ for dust and up to $80 \%$ for sea salt for the simulation BCS2. Convective scavenging accounts for less than $1 \%$ of the global below-cloud removal since convective precipitation covers a much smaller fraction of the model grid boxes as compared to the stratiform precipitation. Simulation BCS2-CPF shows that an alternative to the convec- tive precipitation fraction, as given in Eq. (19), can increase the annual mean convective scavenging by $3-4$ times, but the contribution to total below-cloud scavenging is still only near to $1 \%$. We have used a relatively high and fixed vertical velocity, and this contributes to relatively low convective precipitation fractions, and low convective below-cloud scavenging rates for this study. As convective parameterizations develop, and the representation of subgrid scale effects related to convective clouds is advanced, then improvements can be made to the treatment of convective below-cloud scavenging.

\subsection{Column mass burdens and lifetimes}

Figures 7 and 8 show the geographic distribution of the aerosol burdens for the BCS2 simulation, and a comparison between the CTL and BCS2 simulations. The sea salt and dust burdens are reduced more by the invigorated 

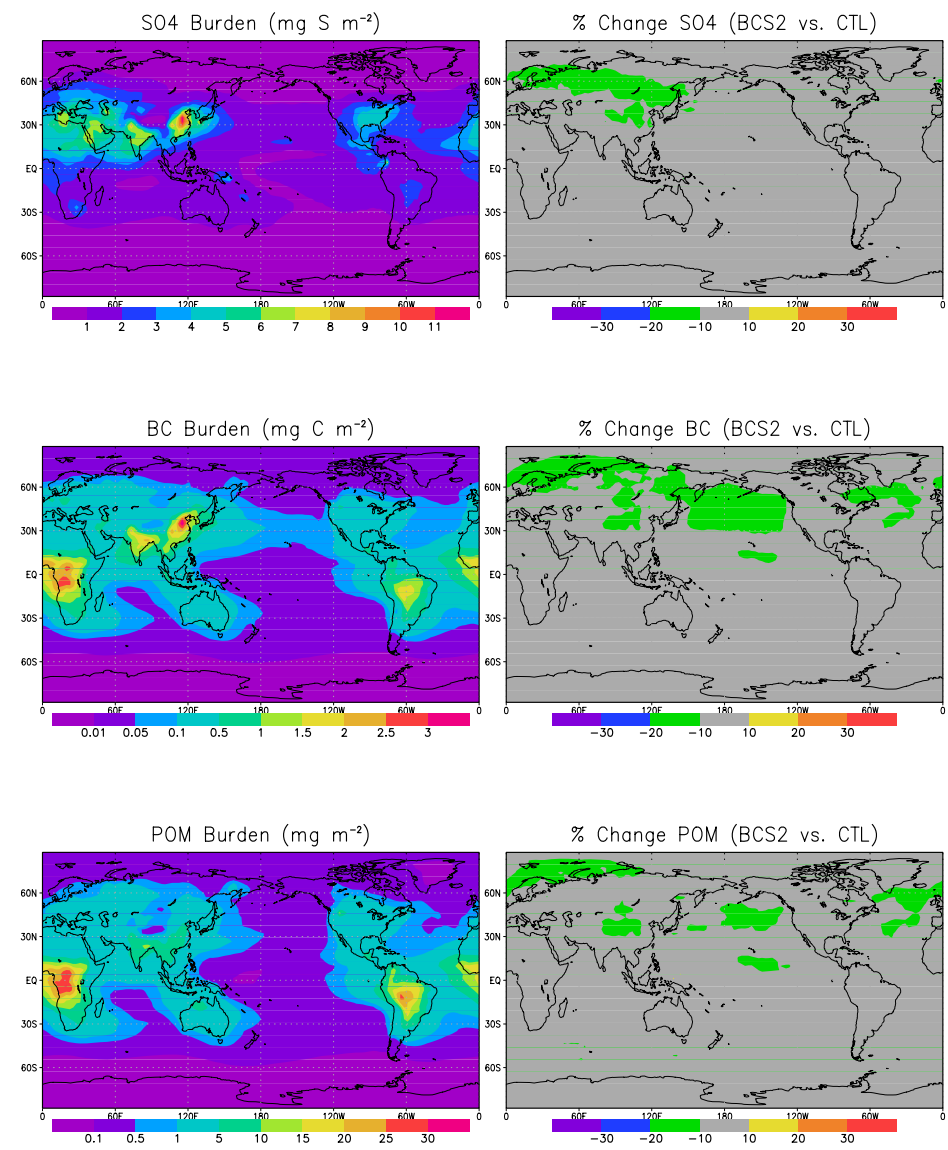

Fig. 7. The geographic distribution of the annual mean burdens of sulfate, black carbon and particulate organic matter for the BCS2 simulation is shown on the left. The percent change relative to the CTL simulation is shown on the right.

below-cloud scavenging than the sulfate and carbonaceous aerosol burdens. Dust burdens are changed by less than $10 \%$ near the major source regions, except for Eur-Asian dust. This is expected since dust is often emitted in regions with low precipitation, and also may be lofted above levels where below-cloud scavenging occurs. However, dust burdens are reduced poleward, and away from the major source regions by up to $30 \%$ in response to the invigorated below-cloud scavenging in the simulation BCS2. One must remember that percent changes should be interpreted by keeping in mind that in some cases the magnitude of the burden and deposition is small, such in this case for dust deposition away from source regions. However, sea salt burdens are reduced by $20-30 \%$ over the major ocean source regions in the BCS2 simulation as compared to the CTL simulation.

Tables 5-9 also present the annual and global mean aerosol burdens and lifetimes. The global and annual mean sea salt burden, and lifetime are reduced by $15-20 \%$ when the sizedependent scavenging parameterizations are implemented. The reductions for the other aerosol species are between
$5-10 \%$. Sea salt is most strongly influenced by the sizedependent below-cloud scavenging parameterizations since this aerosol species has a considerable fraction of total mass in the coarse mode, and the scavenging coefficients for this mode are greatly enhanced, by one to two orders of magnitude, as compared to the prescribed coefficients of Stier et al. (2005) (shown in Fig. 2). Dust also has a considerable mass in the coarse mode, but the lifetime reduction is less, $7 \%$ as opposed to $15 \%$, for sea salt between the BCS2 and CTL simulations. This occurs since dust tends to be emitted in regions of lower precipitation, and is lofted above the altitudes of below-cloud scavenging while being aged to a soluble/mixed state, which can be scavenged by cloud nucleation processes. On the other hand, sea salt emissions are generally in regions of stratiform precipitation, and are more susceptible to removal by below-cloud scavenging shortly after emission. Figure 9 shows that for the BCS1 simulation, which had invigorated below-cloud scavenging by rain only, the dust and sea salt burdens are reduced by less compared to the CTL simulation than for the BCS2 simulation. 

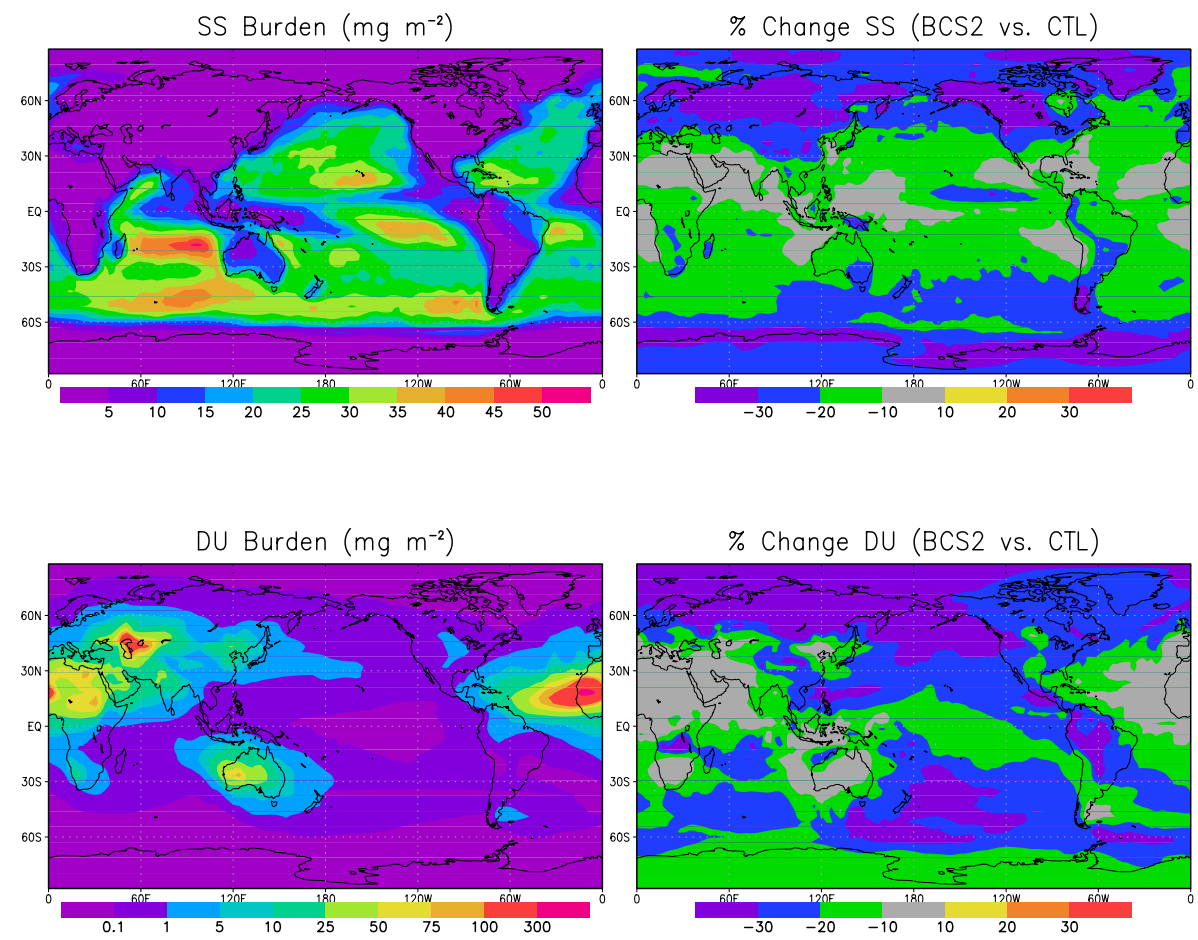

Fig. 8. The geographic distribution of the annual mean burdens of sea salt and dust for the BCS2 simulation is shown on the left. The percent change relative to the CTL simulation is shown on the right.

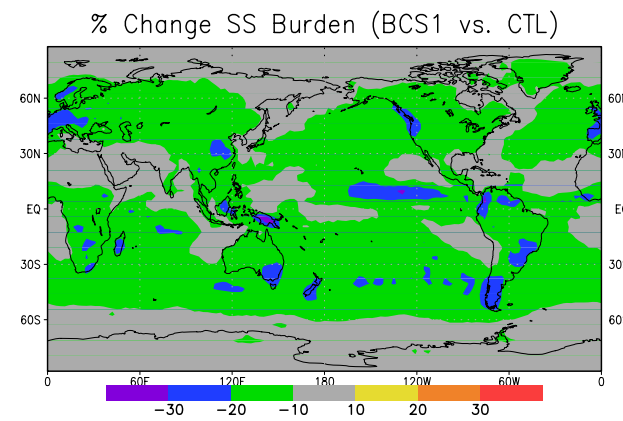

\% Change SS (BCS2-PR vs. CTL)
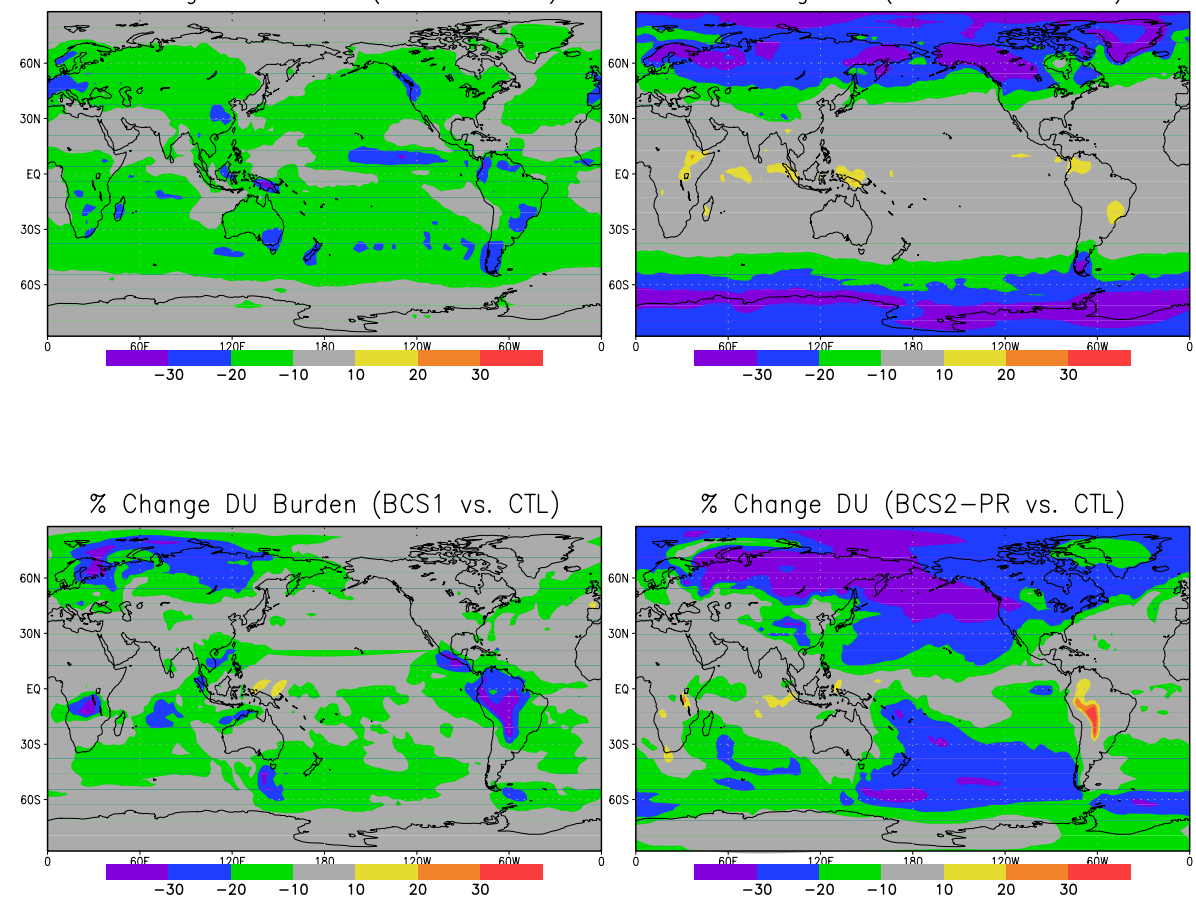

Fig. 9. The percent change of the annual mean burdens of sea salt and dust for the BCS1 and BCS2-PR simulations relative to the CTL simulation. 

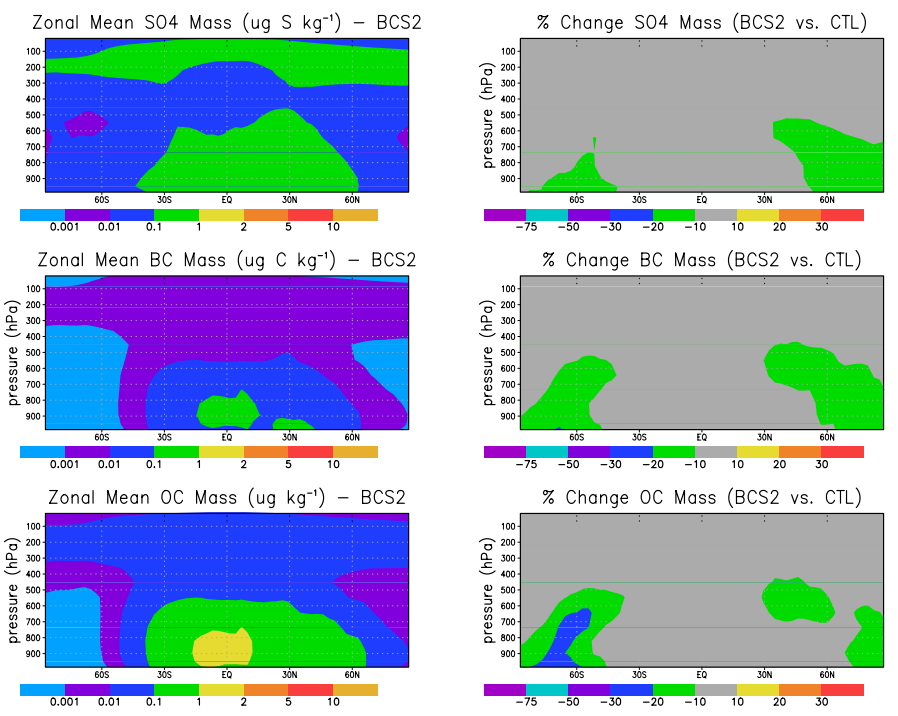

Zonal Mean SS Mass (ug $\mathrm{kg}^{-1}$ )- BCS2
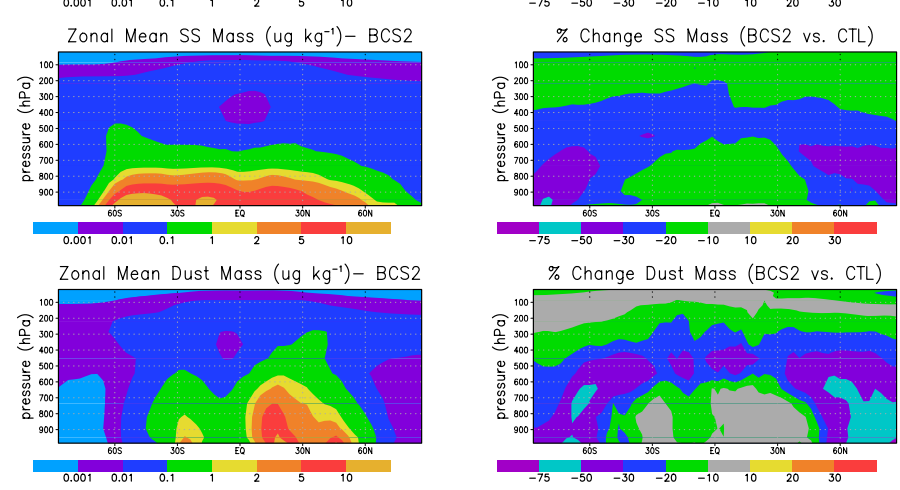

Fig. 10. The annual and zonal mean vertical profiles of the mass mixing ratios of sulfate, black carbon, particulate organic matter, sea salt, and dust for the BCS2 simulation are shown on the left. The percent change relative to the CTL simulation for the BCS2 simulation is shown on the right.

Particularly poleward of $45^{\circ} \mathrm{N}$ and $45^{\circ} \mathrm{S}$, the dust and sea salt burdens are reduced by 10 to $20 \%$ or less in the BCS1 simulation, as opposed to in excess of $20 \%$ for the BCS2 simulation.

Implementation of the prognostic stratiform rain scheme of Posselt and Lohmann (2008) in simulation BCS2-PR has the greatest impact on the annual and global mean sea salt burden. The BCS2-PR simulation is the only simulation that the rain formed in one time-step is not completely removed in that same time-step. Table 8 shows that the sea salt burden is increased as compared to the BCS2 simulation, and is only about $3 \%$ lower than for the CTL simulation. Similar to the other simulations with size-dependent below-cloud scavenging, the below-cloud scavenging is increased and the in-cloud scavenging is reduced for the BCS2-PR simulation relative to the CTL for all aerosol species, but the magnitude of these changes is reduced by near to $50 \%$. Figure 9 shows the geographic distribution of the change in the sea salt and dust burdens in the BCS2-PR simulation relative to the CTL simulation. In comparison to the BCS2 simulation, shown in Fig. 8, there is less reduction in the sea salt mass in the tropics and mid-latitudes. These effects occur since there is increased evaporation fluxes, particularly in the lower troposphere in the BCS2-PR simulation at these warmer latitudes. So there is more efficient release of the aerosols back to the atmosphere, reducing the mass removal by below-cloud scavenging when the prognostic rain scheme is implemented. The dust burden change for the BCS2-PR simulation, as compared to the BCS2 simulation is not as great. This is expected since dust is often lofted higher in the atmosphere prior to wet deposition, or not emitted in regions with high rainfall. Thus, the dust burden is less sensitive to the enhanced evaporation in the lower tropical troposphere in the BCS2-PR simulation.

\subsection{Vertical profiles of aerosol mass and number}

The vertical profiles of the zonal and annual mean mass mixing ratios for the BCS2 simulation are shown in Fig. 10. These mixing ratios are high near their surface sources and decay with altitude, except for the sulfate production at high altitudes in the upper troposphere/lower stratosphere region. 

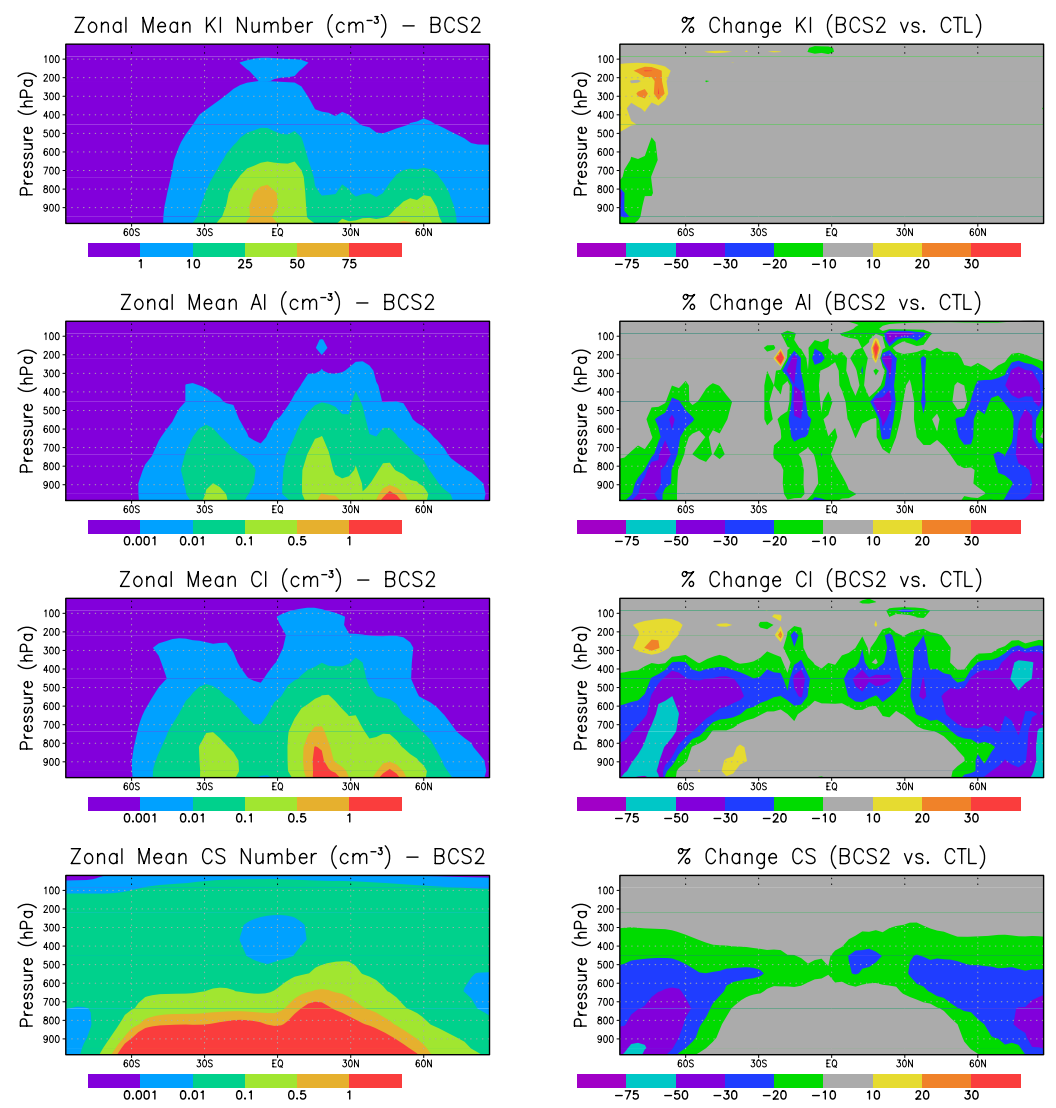

Fig. 11. The annual and zonal mean vertical profiles of number concentration for all insoluble modes, and the internally mixed/soluble coarse mode at standard temperature and pressure for the BCS2 simulation are shown on the left. The percent change relative to the CTL simulation for BCS2 simulations is shown on the right.

In the BCS2 simulation, there is a noted decrease in the mass of dust and sea salt in the middle and upper troposphere (up to $50 \%$ ) as compared to the CTL. This is expected as the below-cloud scavenging is more vigorous in the BCS2 simulation. Again, while the percent change is large, the magnitude of the sea salt and dust burden is small in these regions of the troposphere. Nevertheless, dust acts as an ice nuclei at these levels, and so concentration changes at these altitudes are relevant. The sulfate and carbonaceous aerosol mass is also reduced, particularly by the invigorated belowcloud scavenging by snow. However, this reduction is only up to $20 \%$ and is confined to below $5 \mathrm{~km}$ and poleward of $45^{\circ} \mathrm{N}$ and $45^{\circ} \mathrm{S}$.

The vertical profiles of the aerosol number concentration for all insoluble and the coarse aerosol modes are shown in Fig. 11. The aerosols in the insoluble accumulation, and coarse modes are less numerous by up to $50 \%$ in the BCS2 simulation as compared to the CTL simulation, particularly at those latitudes most influenced by below-cloud scavenging by snow. Aerosols in the insoluble Aitken mode are less changed between the two simulations. Aerosols in the in- ternally mixed/soluble Aitken and accumulation modes were changed by less than $10 \%$ between the BCS2 and CTL simulations, and so are not shown. These aerosols are more efficiently removed by in-cloud scavenging, and are less influenced by the below-cloud scavenging parameterizations. Comparing the BCS1 and CTL simulations, the changes in aerosol number were less than $10 \%$ for all aerosol modes, and are not shown.

Aerosol number burdens are shown in Table 11, the global and annual mean changes are less than $10 \%$. The insoluble aerosols from all modes, and the internally mixed/soluble aerosols of the accumulation and coarse modes are less numerous in all BCS simulations as compared to the CTL simulation. Table 12 shows that the global and annual mean removal of soluble/internally mixed accumulation aerosol number by below-cloud scavenging increases most in response to invigorated below-cloud scavenging by snow, with increases by near to one order of magnitude for the BCS2 simulation compared to the CTL simulation. Inclusion of thermophoretic effects (simulation BCS2-T) most strongly influences the below-cloud scavenging of the Aitken 
Table 4. The simulations presented in this study are summarized in this table.

\begin{tabular}{|c|c|}
\hline Simulation & Description \\
\hline CTL & $\begin{array}{l}\text { Control simulation using prescribed rain and } \\
\text { snow below-cloud scavenging coefficients } \\
\text { from Table } 1\end{array}$ \\
\hline BCS1 & $\begin{array}{l}\text { Prescribed scavenging coefficients for rain } \\
\text { replaced by size-dependent rain scavenging }\end{array}$ \\
\hline $\mathrm{BCS} 2$ & $\begin{array}{l}\text { Same as BCS1 but prescribed scaveng- } \\
\text { ing coefficients for snow replaced by size- } \\
\text { dependent snow scavenging }\end{array}$ \\
\hline BCS2-M0.4 & $\begin{array}{l}\text { Same as BCS2 but assumes all raindrops are } \\
0.4 \mathrm{~mm}\end{array}$ \\
\hline BCS2-M4.0 & $\begin{array}{l}\text { Same as BCS2 but assumes all raindrops are } \\
4.0 \mathrm{~mm}\end{array}$ \\
\hline BCS2-PR & $\begin{array}{l}\text { Same as BCS2 but implements the Posselt } \\
\text { and Lohmann (2008) prognostic rain scheme }\end{array}$ \\
\hline BCS2-CPF & $\begin{array}{l}\text { Same as BCS2 but revised convective precip- } \\
\text { itation fraction }\end{array}$ \\
\hline BCS2-T & $\begin{array}{l}\text { Same as BCS2 but includes thermophoretic } \\
\text { effects }\end{array}$ \\
\hline BCS2-ULOW & $\begin{array}{l}\text { Same as BCS2 but assumes zero collection of } \\
\text { ultra-fine particles with radius }<10 \mathrm{~nm}\end{array}$ \\
\hline BCS2-UHIGH & $\begin{array}{l}\text { Same as BCS } 2 \text { but assumes ultra-fine parti- } \\
\text { cles with radius }<10 \mathrm{~nm} \text { are scavenged like } \\
\text { an irreversibly soluble gas }\end{array}$ \\
\hline
\end{tabular}

Table 5. The global and annual mean sulfate mass deposition rates $\left(\mathrm{Tg} \mathrm{S} \mathrm{yr}^{-1}\right.$ ) for the processes of below-cloud scavenging (BCS), incloud scavenging (ICS), dry deposition, and sedimentation, and sulfate burdens ( $\mathrm{Tg} S$ ), and lifetimes (days) for the model simulations. See Table 4 for descriptions of the simulations. The annual emission and production of sulfate is about $73.5 \mathrm{Tg} \mathrm{S} \mathrm{yr}^{-1}$.

\begin{tabular}{lllllll}
\hline Sulfate Deposition & BCS & ICS & Dry Dep & Sed & Burden & Lifetime \\
\hline CTL & 0.23 & 69.4 & 2.32 & 1.59 & 0.88 & 4.37 \\
BCS1 & 7.02 & 63.0 & 2.12 & 1.35 & 0.85 & 4.24 \\
BCS2 & 9.90 & 60.2 & 2.09 & 1.29 & 0.84 & 4.17 \\
BCS2-M0.4 & 16.2 & 54.1 & 1.93 & 1.14 & 0.81 & 4.03 \\
BCS2-M4.0 & 6.96 & 62.9 & 2.18 & 1.42 & 0.85 & 4.24 \\
BCS2-PR & 3.79 & 65.3 & 2.35 & 1.53 & 0.86 & 4.29 \\
BCS2-CPF & 9.99 & 60.1 & 2.08 & 1.28 & 0.84 & 4.17 \\
BCS2-T & 9.99 & 60.1 & 2.09 & 1.29 & 0.84 & 4.17 \\
BCS2-ULOW & 9.90 & 60.2 & 2.09 & 1.28 & 0.84 & 4.17 \\
BCS2-UHIGH & 9.90 & 60.2 & 2.08 & 1.29 & 0.84 & 4.17 \\
\hline
\end{tabular}

size particles. This is expected since Aitken size aerosols lie in the Greenfield scavenging gap, and thus are most sensitive to thermophoretic effects. The global and annual mean number removal of Aitken size aerosols by below-cloud scavenging was increased by near to $10 \%$ for the BCS2-T simulation compared to the BCS2 simulation. Table 12 shows that the enhanced ultra-fine scavenging in simulation BCS2-UHIGH gives the highest below-cloud number removal of the nucleation mode, but the number burden for this mode is slightly
Table 6. Global and annual mean black carbon mass deposi-

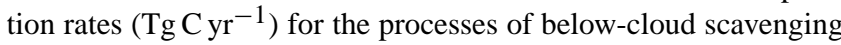
(BCS), in-cloud scavenging (ICS), dry deposition, and sedimentation, and black carbon burdens ( $\mathrm{TgC}$ ), and lifetimes (days) for the model simulations. See Table 4 for descriptions of the simulations. The annual emission of black carbon is $7.7{\mathrm{Tg} \mathrm{C} \mathrm{yr}^{-1}}^{-1}$.

\begin{tabular}{lllllll}
\hline BC Deposition & BCS & ICS & Dry Dep & Sed & Burden & Lifetime \\
\hline CTL & 0.01 & 7.01 & 0.72 & 0.027 & 0.120 & 5.69 \\
BCS1 & 0.68 & 6.35 & 0.70 & 0.025 & 0.119 & 5.64 \\
BCS2 & 0.98 & 6.06 & 0.70 & 0.024 & 0.118 & 5.59 \\
BCS2-M0.4 & 1.68 & 5.37 & 0.69 & 0.023 & 0.114 & 5.54 \\
BCS2-M4.0 & 0.70 & 6.33 & 0.71 & 0.025 & 0.120 & 5.69 \\
BCS2-PR & 0.39 & 6.63 & 0.72 & 0.026 & 0.116 & 5.50 \\
BCS2-CPF & 0.99 & 6.05 & 0.70 & 0.024 & 0.117 & 5.54 \\
BCS2-T & 0.99 & 6.05 & 0.70 & 0.024 & 0.117 & 5.54 \\
BCS2-ULOW & 0.98 & 6.06 & 0.70 & 0.024 & 0.118 & 5.59 \\
BCS2-UHIGH & 0.98 & 6.06 & 0.70 & 0.024 & 0.118 & 5.59 \\
\hline
\end{tabular}

Table 7. Global and annual mean particulate organic matter mass deposition rates $\left(\mathrm{Tg} \mathrm{yr}^{-1}\right)$ for the processes of below-cloud scavenging (BCS), in-cloud scavenging (ICS), dry deposition, and sedimentation, and particulate organic matter burdens ( $\mathrm{Tg}$ ), and lifetimes (days) for the model simulations. See Table 4 for descriptions of the simulations. The annual emission of particulate organic matter is $66.1 \mathrm{Tg} \mathrm{C} \mathrm{yr}^{-1}$.

\begin{tabular}{lllllll}
\hline POM Deposition & BCS & ICS & Dry Dep & Sed & Burden & Lifetime \\
\hline CTL & 0.08 & 60.0 & 5.91 & 0.21 & 1.05 & 5.78 \\
BCS1 & 5.11 & 55.1 & 5.87 & 0.20 & 1.03 & 5.69 \\
BCS2 & 6.58 & 53.6 & 5.86 & 0.20 & 1.02 & 5.64 \\
BCS2-M0.4 & 12.6 & 47.7 & 5.80 & 0.19 & 0.99 & 5.48 \\
BCS2-M4.0 & 4.42 & 55.7 & 5.89 & 0.20 & 1.03 & 5.69 \\
BCS2-PR & 2.02 & 58.1 & 5.98 & 0.20 & 1.01 & 5.56 \\
BCS2-CPF & 6.66 & 53.5 & 5.85 & 0.20 & 1.02 & 5.64 \\
BCS2-T & 6.66 & 53.5 & 5.85 & 0.19 & 1.02 & 5.64 \\
BCS2-ULOW & 6.58 & 53.6 & 5.86 & 0.20 & 1.02 & 5.64 \\
BCS2-UHIGH & 6.57 & 53.6 & 5.87 & 0.20 & 1.02 & 5.64 \\
\hline
\end{tabular}

increased, by less than $1 \%$ relative to the CTL simulation (see Table 11). The nucleation mode number burden is dominated by upper tropospheric concentrations (Stier et al., 2005) that are not strongly influenced by scavenging by below-cloud scavenging processes.

To better understand the increase in the global and annual mean nucleation number burden, we present Fig. 12. Figure 12 shows the vertical profile of the fractional change in the zonal and annual mean nucleation mode number concentrations for the various simulations as compared to the CTL simulation. In the lower troposphere, as below-cloud scavenging is more vigorous we find that zonal mean nucleation mode number concentrations are increased by up to $30 \%$. This is expected since the more vigorous below-cloud scavenging will reduce the available condensation surfaces of the accumulation and coarse modes, and new particle formation will be enhanced, as opposed to sulfuric acid condensation on available surfaces. The competing, but less dominant 

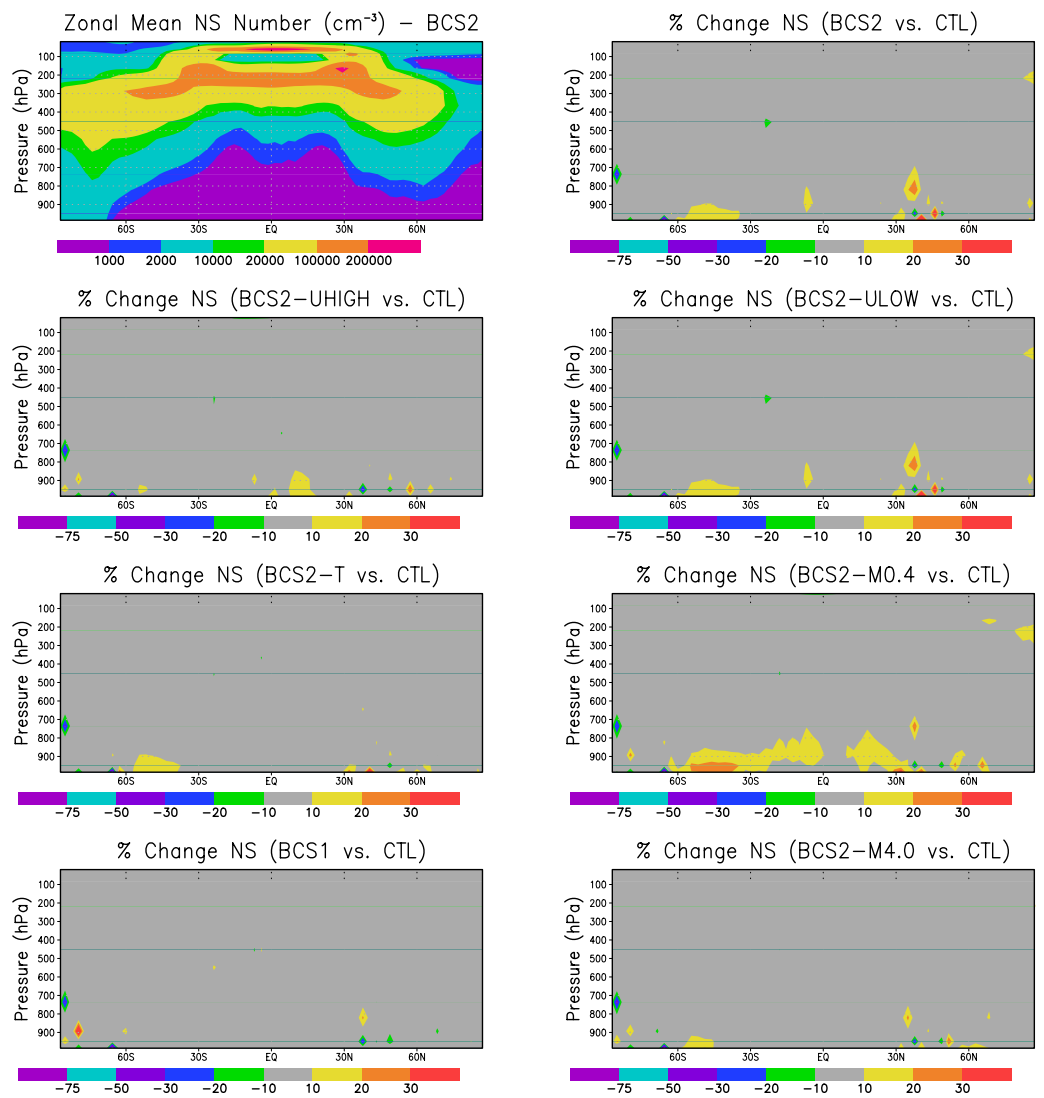

Fig. 12. The annual and zonal mean vertical profile of nucleation mode number concentration at standard temperature and pressure, and the percent change relative to the CTL simulation for the simulations BCS2, BCS2-UHIGH, BCS2-ULOW, BCS2-T, BCS2-M0.4, BCS2-M4.0 and BCS1.

Table 8. Global and annual mean sea salt mass deposition rates $\left(\mathrm{Tg} \mathrm{yr}^{-1}\right)$ for the processes of below-cloud scavenging (BCS), incloud scavenging (ICS), dry deposition, and sedimentation, and sea salt burdens ( $\mathrm{Tg}$ ), and lifetimes (days) for the model simulations. See Table 4 for descriptions of the simulations. The annual emission of sea salt is about $5350 \mathrm{Tg} \mathrm{yr}^{-1}$.

\begin{tabular}{lllllll}
\hline SS Deposition & BCS & ICS & Dry Dep & Sed & Burden & Lifetime \\
\hline CTL & 153. & 2440. & 1220. & 1600. & 9.95 & 0.67 \\
BCS1 & 1040. & 2070. & 987. & 1310. & 8.60 & 0.58 \\
BCS2 & 1250. & 1930. & 950. & 1270. & 8.37 & 0.57 \\
BCS2-M0.4 & 1870. & 1670. & 774. & 1090. & 7.27 & 0.49 \\
BCS2-M4.0 & 755. & 2140. & 1080. & 1430. & 9.21 & 0.62 \\
BCS2-PR & 366 & 2200. & 1190. & 1610. & 9.65 & 0.66 \\
BCS2-CPF & 1260. & 1930. & 949. & 1270. & 8.36 & 0.57 \\
BCS2-T & 1250. & 1930. & 950. & 1270. & 8.38 & 0.57 \\
BCS2-LOW & 1250. & 1930. & 950. & 1270. & 8.37 & 0.57 \\
BCS2-HIGH & 1250. & 1930. & 950. & 1270. & 8.37 & 0.57 \\
\hline
\end{tabular}

factor is the higher nucleation mode below-cloud scavenging for the size-dependent simulations relative to the control, which would reduce the nucleation mode number. The lower
Table 9. Global and annual mean dust mass deposition rates $\left(\mathrm{Tg} \mathrm{yr}^{-1}\right)$ for the processes of below-cloud scavenging (BCS), incloud scavenging (ICS), dry deposition, and sedimentation, and dust burdens (Tg), and lifetimes (days) for the model simulations. See Table 4 for descriptions of the simulations. The annual emission of dust is about $330 \mathrm{Tg} \mathrm{yr}^{-1}$.

\begin{tabular}{lllllll}
\hline DU Deposition & BCS & ICS & Dry Dep & Sed & Burden & Lifetime \\
\hline CTL & 12.7 & 169. & 23.4 & 129. & 3.78 & 4.15 \\
BCS1 & 51.4 & 137. & 21.6 & 124. & 3.64 & 3.99 \\
BCS2 & 78.2 & 113. & 21.2 & 121. & 3.52 & 3.86 \\
BCS2-M0.4 & 101. & 93.8 & 20.2 & 117. & 3.39 & 3.72 \\
BCS2-M4.0 & 60.6 & 123. & 22.0 & 123. & 3.62 & 3.97 \\
BCS2-PR & 39.2 & 143. & 24.3 & 128. & 3.65 & 4.00 \\
BCS2-CPF & 79.9 & 113. & 21.1 & 121. & 3.55 & 3.89 \\
BCS2-T & 79.2 & 113. & 21.3 & 121. & 3.54 & 3.88 \\
BCS2-LOW & 78.2 & 113. & 21.2 & 121. & 3.52 & 3.86 \\
BCS2-HIGH & 78.0 & 113. & 21.3 & 121. & 3.53 & 3.87 \\
\hline
\end{tabular}

tropospheric nucleation mode number concentrations have the greatest increase for the simulation BCS2-M0.4, which had the strongest scavenging of the accumulation and coarse modes. This is particularly evident over the southern oceans. 

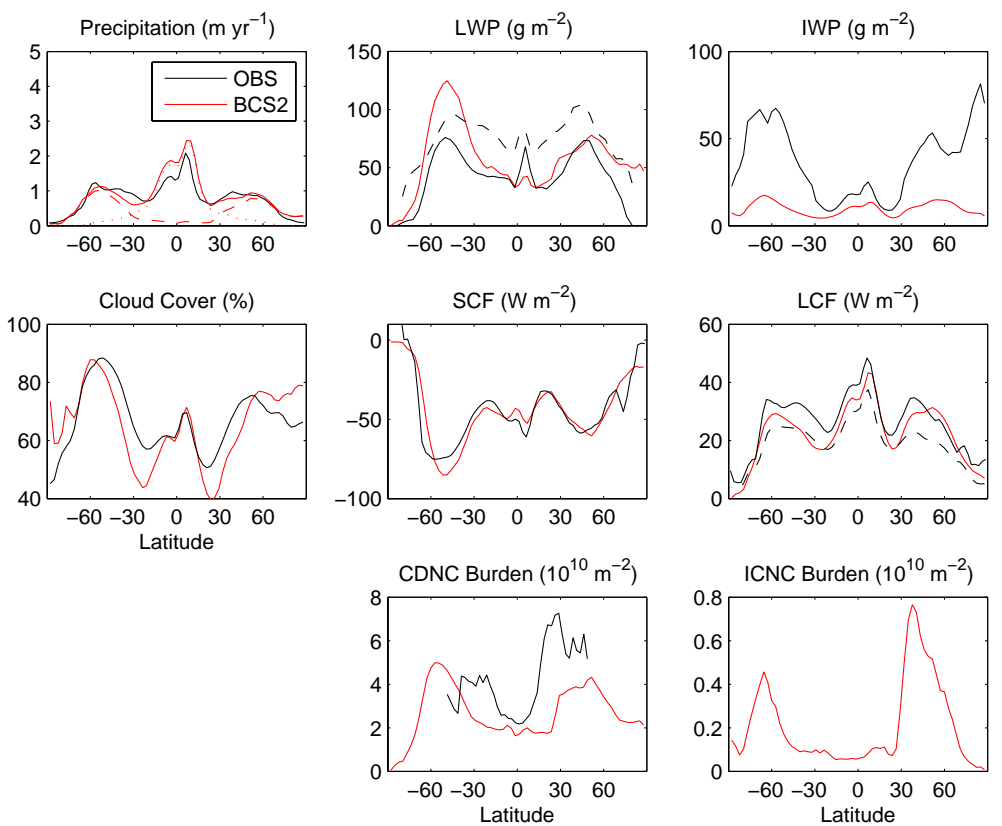

Fig. 13. The annual and zonal mean precipitation, mean liquid water path (LWP), ice water path (IWP), cloud cover (CC), short wave cloud forcing (SCF), long wave cloud forcing (LCF), vertically integrated cloud droplet number concentration (CDNC) and vertically integrated ice crystal number concentration (ICNC) for the BCS2 simulation and observations. The sources of the observations are described in Table 13. For precipitation, dashed line:stratiform, dotted line:convective. For LWP observations, solid black: Weng and Grody (1994), dashed black: Greenwald et al. (1993). For LCF, solid black: ERBE, dashed black: TOVS data. The SCF is from ERBE data.

Table 10. Global and annual mean deposition rates $\left(\mathrm{Tg} \mathrm{yr}^{-1}\right)$ for the processes of below-cloud scavenging by stratiform rain (StratRain), stratiform snow (Strat-Snow), convective rain (Conv-Rain) and convective snow (Conv-Snow). The five aerosol species are sulfate (SO4), black carbon (BC), particulate organic matter (POM), dust (DU), and sea salt (SS). See Table 4 for descriptions of the simulations.

\begin{tabular}{rrrrr}
\hline & Strat-Rain & Strat-Snow & Conv-Rain & Conv-Snow \\
\hline SO4-CTL & 0.20 & 0.03 & 0.002 & $<0.00001$ \\
SO4-BCS1 & 6.97 & 0.02 & 0.03 & $<0.00001$ \\
SO4-BCS2 & 6.97 & 2.93 & 0.03 & 0.001 \\
SO4-BCS2-CPF & 6.96 & 2.94 & 0.11 & 0.003 \\
\hline BC-CTL & 0.006 & 0.005 & $<0.00001$ & $<0.00001$ \\
BC-BCS1 & 0.68 & 0.004 & 0.003 & $<0.00001$ \\
BC-BCS2 & 0.68 & 0.30 & 0.003 & 0.00007 \\
BC-BCS2-CPF & 0.68 & 0.30 & 0.012 & 0.0002 \\
\hline POM-CTL & 0.05 & 0.02 & 0.0006 & $<0.00001$ \\
POM-BCS1 & 5.1 & 0.02 & 0.03 & $<0.00001$ \\
POM-BCS2 & 5.1 & 1.4 & 0.03 & 0.0003 \\
POM-BCS2-CPF & 5.1 & 1.4 & 0.12 & 0.0007 \\
\hline DU-CTL & 12.3 & 0.2 & 0.2 & $<0.00001$ \\
DU-BCS1 & 50.6 & 0.19 & 0.6 & $<0.00001$ \\
DU-BCS2 & 49.7 & 28.3 & 0.6 & 0.02 \\
DU-BCS2-CPF & 49.5 & 28.8 & 1.9 & 0.03 \\
\hline SS-CTL & 151. & 1.0 & 0.64 & 0.001 \\
SS-BCS1 & 1040. & 0.9 & 2.7 & 0.001 \\
SS-BCS2 & 1020. & 238. & 2.7 & 0.9 \\
SS-BCS2-CPF & 1020. & 238. & 11.7 & 2.8 \\
\hline
\end{tabular}

www.atmos-chem-phys.net/9/4653/2009/
Table 11. Global and annual mean number burdens in $10^{10} \mathrm{~m}^{-2}$ for the 7 aerosol modes for the model simulations. See Table 4 for descriptions of the simulations.

\begin{tabular}{llllllll}
\hline Number & NS & KS & AS & CS & KI & AI & CI \\
\hline CTL & 18400 & 830. & 74.4 & 0.46 & 8.58 & 0.032 & 0.068 \\
BCS1 & 18430 & 830. & 74.5 & 0.46 & 8.52 & 0.031 & 0.068 \\
BCS2 & 18510 & 832. & 74.3 & 0.45 & 8.48 & 0.031 & 0.066 \\
BCS2-M0.4 & 18570 & 831. & 74.3 & 0.43 & 8.39 & 0.031 & 0.066 \\
BCS2-M4.0 & 18430 & 832. & 74.5 & 0.45 & 8.53 & 0.031 & 0.067 \\
BCS2-PR & 18222 & 837. & 74.8 & 0.46 & 8.20 & 0.031 & 0.066 \\
BCS2-CPF & 18470 & 832. & 74.3 & 0.45 & 8.49 & 0.031 & 0.067 \\
BCS2-T & 18490 & 832. & 74.5 & 0.45 & 8.49 & 0.031 & 0.066 \\
BCS2-ULOW & 18510 & 832. & 74.3 & 0.45 & 8.48 & 0.031 & 0.066 \\
BCS2-UHIGH & 18440 & 831. & 74.5 & 0.45 & 8.45 & 0.031 & 0.066 \\
\hline
\end{tabular}

For the simulation BCS2-UHIGH, the invigorated scavenging of particles less than $10 \mathrm{~nm}$ has reduced the magnitude of this effect over the southern oceans. Unfortunately, our simulations did not diagnose vertical profiles of new particle nucleation rates. However, Fig. 2 shows that the size-dependent simulations use higher below-cloud scavenging coefficients for the nucleation mode relative to the CTL simulation, except for simulation BCS2-M4.0. Thus the increase in nucleation mode number can not arise from lower nucleation mode scavenging for the size-dependent scavenging simulations, but rather enhanced particle formation in the lower troposphere. 

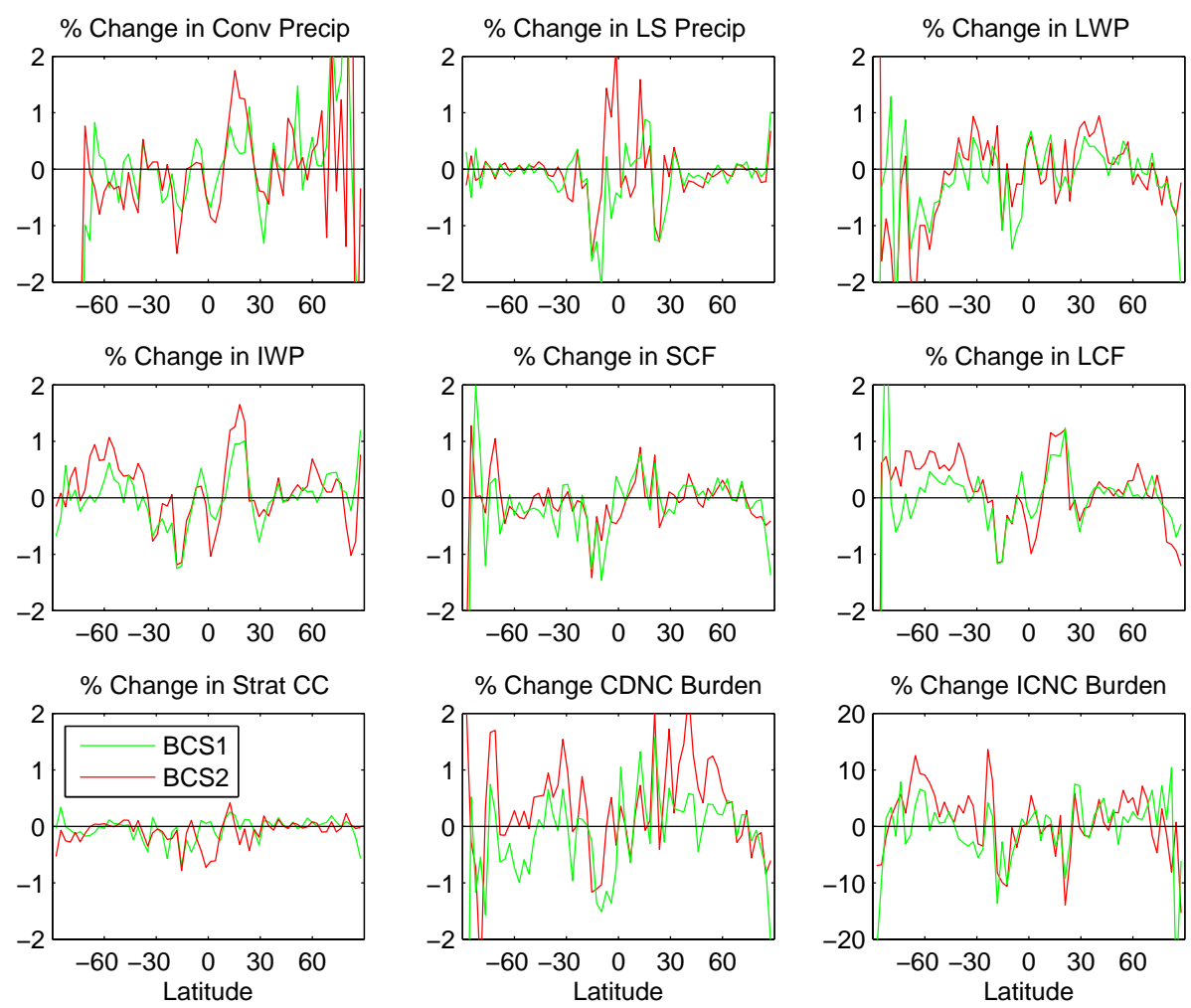

Fig. 14. The percent change in convective and stratiform precipitation, liquid water path (LWP), ice water path (IWP), shortwave cloud forcing (SCF), longwave cloud forcing (LCF), stratiform cloud cover, vertically integrated cloud droplet number concentration (CDNC), and vertically integrated ice crystal number concentration (ICNC) relative to the CTL simulation for the BCS1 and BCS2 simulations.

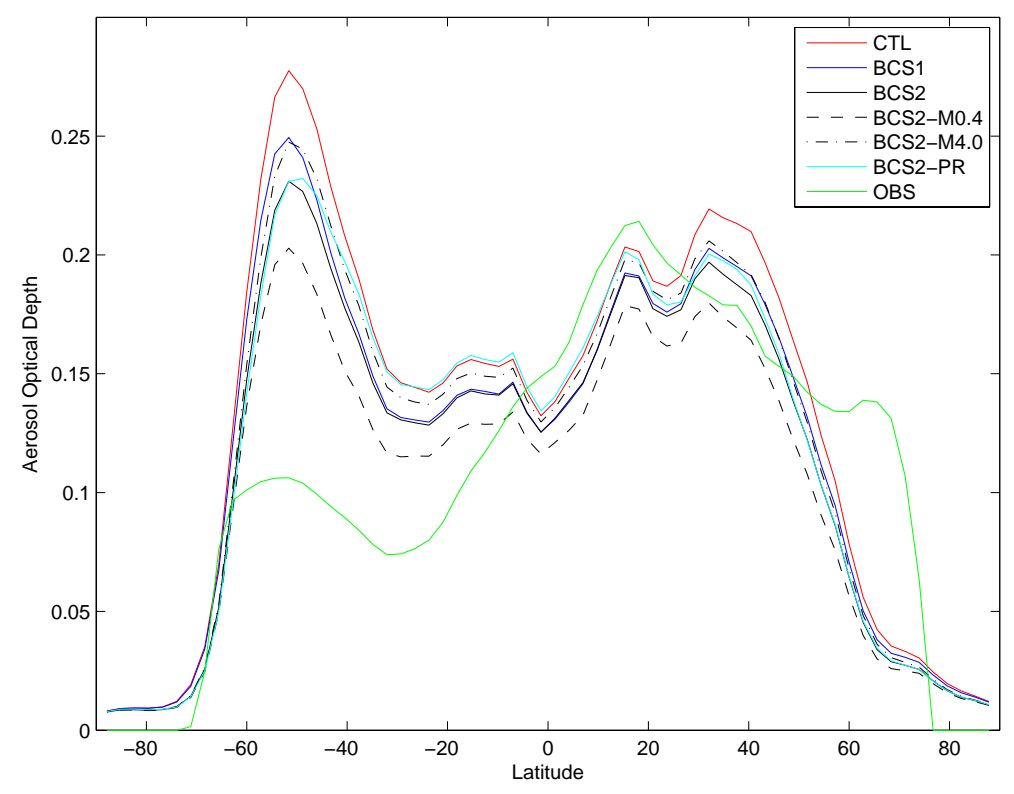

Fig. 15. The annual and zonal mean aerosol optical depth at $550 \mathrm{~nm}$ from the CTL, BCS1, BCS2, BCS2-M0.4, BCS2-M4.0, and BCS2-PR simulations is shown in comparison to the composite of observations from MODIS, MISR and AERONET prepared by Kinne (2009). 

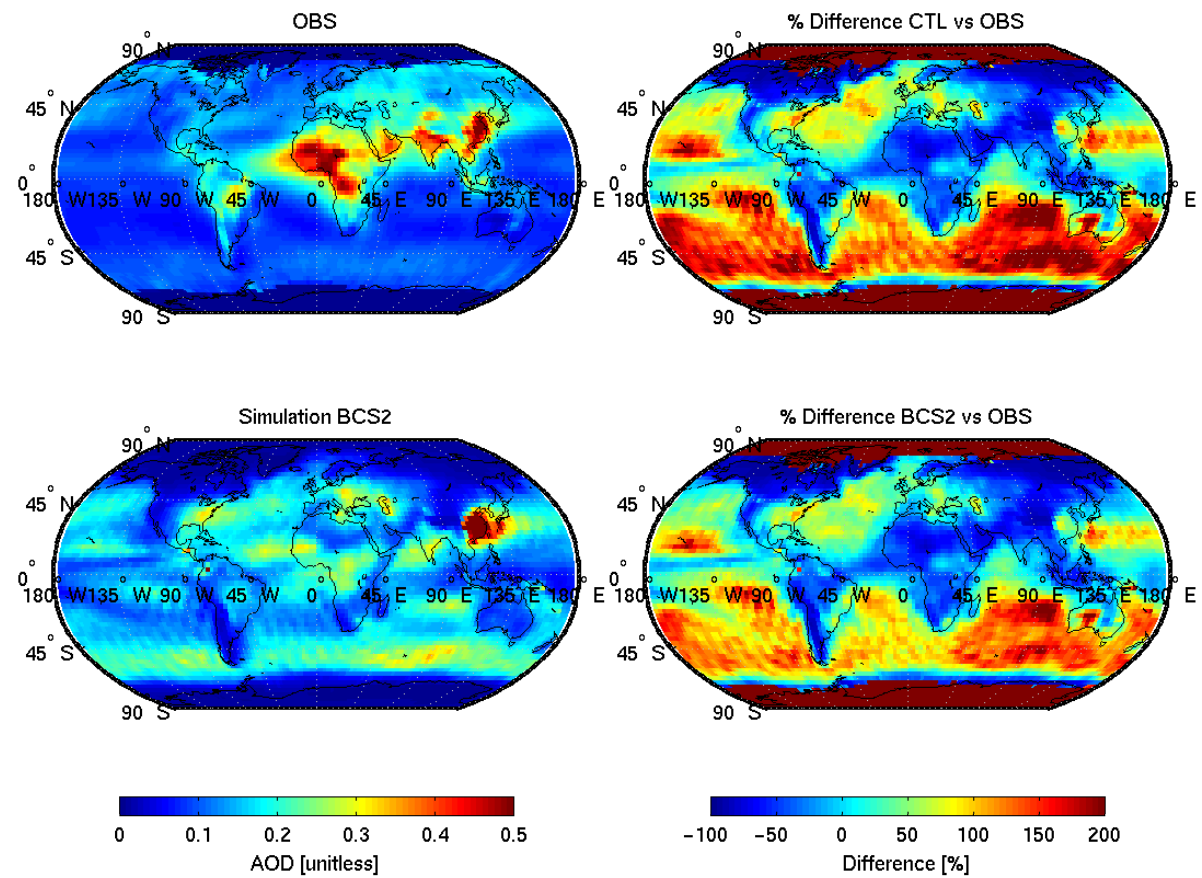

Fig. 16. The geographic distribution of the annual mean aerosol optical depth at $550 \mathrm{~nm}$ for the MODIS MISR AERONET composite observations, and for the BCS2 simulation is shown on the left. On the right is the percent difference for the CTL and BCS2 simulations as compared to the observations.

Table 12. Global and annual mean number removal by below-cloud scavenging $\left(10^{3} \mathrm{~m}^{-2} \mathrm{~s}^{-1}\right)$ for the 7 aerosol modes for the model simulations. See Table 4 for descriptions of the simulations.

\begin{tabular}{llllllll}
\hline Deposition & NS & KS & AS & CS & KI & AI & CI \\
\hline CTL & 33.8 & 7.2 & 1.2 & 1.6 & 0.41 & 0.002 & 0.09 \\
BCS1 & 193. & 10.0 & 1.1 & 1.9 & 0.61 & 0.002 & 0.10 \\
BCS2 & 572. & 14.6 & 13.5 & 4.3 & 0.84 & 0.007 & 0.21 \\
BCS2-M0.4 & 699. & 14.8 & 13.0 & 6.5 & 0.80 & 0.007 & 0.20 \\
BCS2-M4.0 & 574. & 12.7 & 13.6 & 3.6 & 0.66 & 0.007 & 0.22 \\
BCS2-PR & 660. & 13.8 & 13.4 & 2.8 & 0.73 & 0.006 & 0.22 \\
BCS2-CPF & 758. & 15.7 & 13.6 & 4.3 & 0.89 & 0.007 & 0.22 \\
BCS2-T & 753. & 15.7 & 13.7 & 4.3 & 0.88 & 0.007 & 0.21 \\
BCS2-ULOW & 575. & 14.6 & 13.5 & 4.3 & 0.84 & 0.007 & 0.21 \\
BCS2-UHIGH & 2320. & 135. & 13.6 & 4.3 & 6.59 & 0.007 & 0.21 \\
\hline
\end{tabular}

\subsection{Impacts on cloud properties and precipitation}

We have seen that changes in the below-cloud scavenging parameterization can cause changes in the aerosol number vertical profiles. These effects are greatest for the insoluble aerosols, which do not act as cloud condensation nuclei in our model, but can be ice nuclei. In this section we investigate if the changes in aerosol number cause any feedback on the cloud properties. In our framework of nudged simulations, we will only see changes in the clouds that occur primarily in response to changes in the aerosol number.
Changes in the clouds in response to dynamical changes will not be significant since the large-scale meteorological state of the model is nudged to the observations. Additionally, we must use caution in interpreting these feedbacks since the nudging of the meteorological state of the model can reduce the magnitude of the aerosol-cloud-precipitation feedbacks themselves. Thus, this can not be a true feedback study and should not be interpreted in a broad sense. In this section we aim to investigate the extent that these aerosol-cloud feedbacks did occur in the framework of our nudged simulations.

Figure 13 shows the annual and zonal mean liquid and ice water paths, cloud cover, precipitation, cloud droplet and ice crystal number concentrations and cloud forcing from the BCS2 simulation and from observations. We can see that there is a reasonable agreeable with observations. The changes in these properties between the various simulations are easier to appreciate in terms of the percent change relative to the CTL simulation, which is shown in Fig. 14. For the BCS1 and BCS2 simulations compared to the CTL simulation, changes in the various cloud properties are $2 \%$ or less, except for the ice crystal number concentration, which fluctuates by up to $10 \%$. Ice crystal number concentrations are sensitive to the changes in insoluble aerosol concentrations, which are influenced to a greater extent by the below-cloud scavenging parameterizations. In the zonal band near $20^{\circ} \mathrm{N}$, there appears to be an invigoration of the convective precipitation of near to $2 \%$. This contibutes to the increased wet 

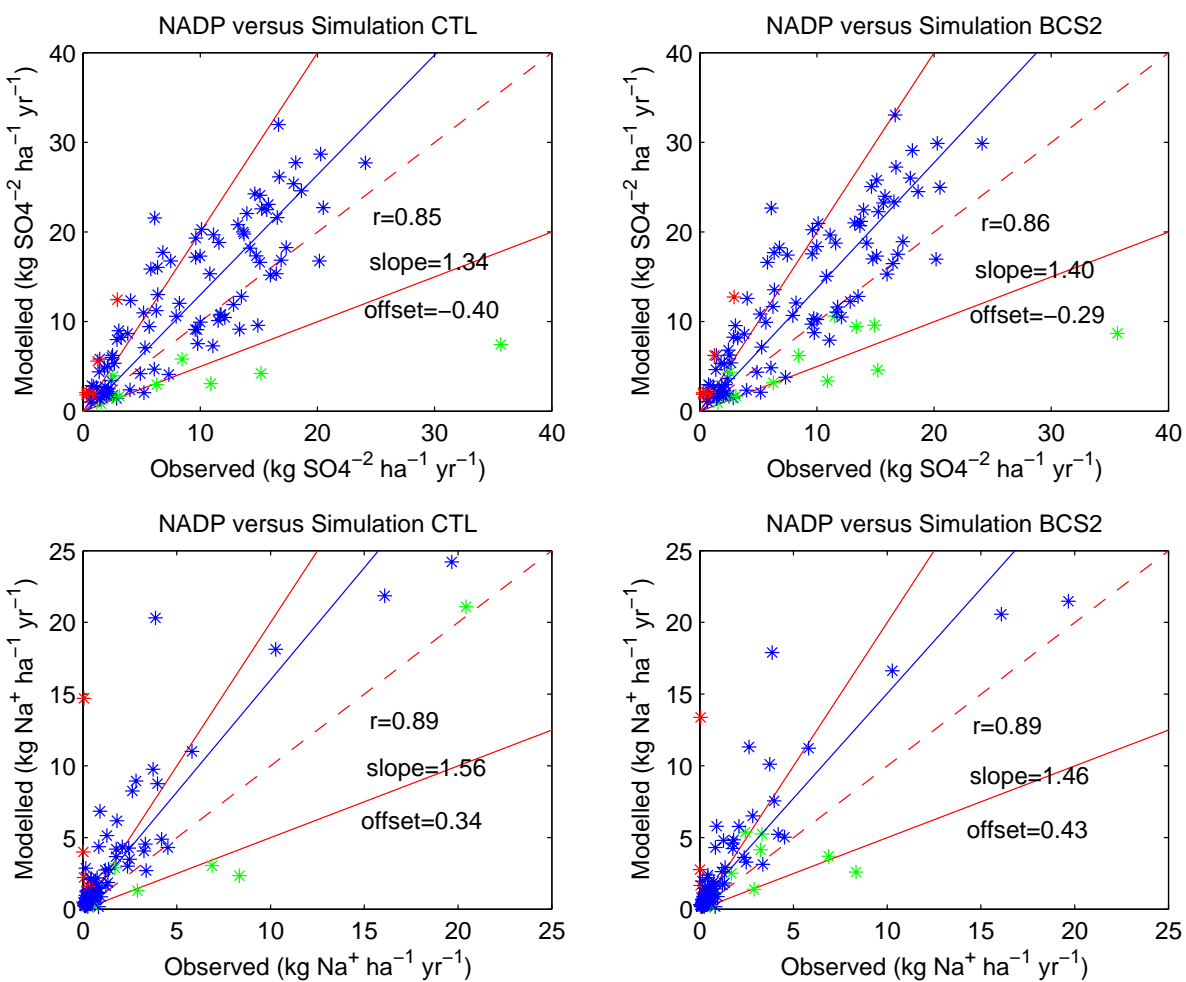

Fig. 17. The observed annual mean sulfate deposition for $2001\left(\mathrm{~kg} \mathrm{SO}_{4}^{-2} \mathrm{ha}^{-1} \mathrm{yr}^{-1}\right)$ from the National Atmospheric Deposition Program (NADP) of the United States in comparison to the CTL and BCS2 simulations is on the top 2 panels. The observed annual mean sodium ion deposition for $2001\left(\mathrm{ka} \mathrm{Na}^{+} \mathrm{ha}^{-1} \mathrm{yr}^{-1}\right)$ from the NADP in comparison to the CTL and BCS2 simulations is on the bottom 2 panels. Red and green asterisks: Modelled precipitation over- and under-predicts observed precipitation, respectively, by a factor of two or greater, and excluded from statistics.

Table 13. Global and annual mean liquid water path (LWP) $\left(\mathrm{kg} \mathrm{m}^{-2}\right)$, ice water path (IWP) $\left(\mathrm{kg} \mathrm{m}^{-2}\right)$, cloud cover (CC), precipitation, cloud droplet number concentration $\left(\mathrm{N}_{d}\right)\left(\mathrm{cm}^{-3}\right)$, and ice crystal number concentration $\left(\mathrm{N}_{i}\right)\left(\mathrm{cm}^{-3}\right)$. LWP observations are from SSM/I (Greenwald et al., 1993; Weng and Grody, 1994; Ferraro et al., 1996). IWP has been derived from ISCCP (Storelvmo et al., 2008). Total cloud cover is from ISCCP (Rossow and Schiffer, 1999) and total precipitation is from the Global Precipitation DataSet. Observations of $\mathrm{N}_{d}$ are from ISCCP (Han et al., 1998).

\begin{tabular}{llllllll}
\hline & LWP & IWP & CC & Precip & $\mathrm{N}_{d}$ & $\mathrm{~N}_{i}$ & AOD \\
\hline OBS & $49-84$ & & $62-67$ & $2.64-2.7$ & 4 & & 0.15 \\
MODIS/TOVS & $94-109$ & & $65-67$ & & & & $0.18-0.19$ \\
CTL & 66.7 & 9.42 & 61.7 & 2.88 & 2.56 & 0.199 & 0.161 \\
BCS1 & 66.6 & 9.42 & 61.6 & 2.88 & 2.56 & 0.202 & 0.148 \\
BCS2 & 66.7 & 9.43 & 61.6 & 2.88 & 2.58 & 0.204 & 0.143 \\
BCS2-M0.4 & 66.7 & 9.44 & 61.6 & 2.88 & 2.59 & 0.206 & 0.129 \\
BCS2-M4.0 & 66.8 & 9.43 & 61.7 & 2.88 & 2.57 & 0.202 & 0.151 \\
BCS2-PR & 49.8 & 9.29 & 61.6 & 2.87 & 2.17 & 0.180 & 0.151 \\
BCS2-CPF & 66.8 & 9.44 & 61.6 & 2.88 & 2.58 & 0.205 & 0.143 \\
BCS2-T & 66.7 & 9.44 & 61.6 & 2.88 & 2.57 & 0.204 & 0.143 \\
BCS2-ULOW & 66.7 & 9.43 & 61.6 & 2.88 & 2.58 & 0.204 & 0.143 \\
BCS2-UHIGH & 66.4 & 9.42 & 61.6 & 2.88 & 2.56 & 0.201 & 0.143 \\
\hline
\end{tabular}


deposition near these latitudes seen in Figs. 5 and 6. This regionally increased precipitation is also shown on Fig. 6 .

Table 13 shows the annual and global mean cloud liquid and ice water paths, precipitation, cloud droplet, and ice crystal number concentrations. Invigorated below-cloud scavenging by snow in the BCS2 simulations as compared to the CTL simulations is associated with very small, (near 1\%) increases in the global and annual cloud droplet and ice crystal number concentrations, and ice water path. This is associated with a small increase in the number of internally mixed/soluble Aitken size aerosols as shown in Table 11. In the global mean, the longwave cloud forcing is slightly increased, but the magnitude of this change on a global scale is less than $1 \%$ and is not shown in the table. Thus, for these nudged simulations we find that changes in the aerosol number induced by different below-cloud scavenging parameterizations are not sufficient to alter the global mean cloud properties by themselves alone without feedbacks on the meteorology. Nevertheless, though the large-scale cloud properties are not strongly affected by the modified below-cloud scavenging for our simulations, there are smaller scale local events, such as over Northern Africa, that due to model non-linearities can increase and modify the climate system. These small local changes in the hydrological cycle can additionally impact on dust mobilization that is dependent on recent occurrences of rainfall. These are factors that can not be completely controlled between our simulations, but contribute to differences in the aerosol wet deposition to a limited extent for our nudged simulations. While simulations with fixed cloud droplet and ice crystal number concentrations are possible, the climatology of the model deteriorates with such simulations, which is not desirable for comparisons with observations, such as in the following section.

\subsection{Comparison with AOD and deposition observation}

Figure 15 shows the annual and zonal mean aerosol optical depth (AOD) at $550 \mathrm{~nm}$ from a composite of MODIS (over oceans), MISR (over land), and AERONET observations (Kinne, 2009), and for the various simulations. The invigorated below-cloud scavenging produces a reduction in the AOD by near to $15 \%$. This is also shown in the global and annual mean in Table 13. The change in AOD between simulations is greatest in the southern hemisphere where the AOD is dominated by sea salt, which has a mass burden that is most strongly influenced by below-cloud scavenging. The used version of the ECHAM5-HAM model has a bias towards excessive sea salt AOD that is not fully corrected by modifications to the below-cloud scavenging parameterization. However, the implementation of size-dependent belowcloud scavenging does reduce this bias. In the northern hemisphere the simulations agree more closely with the observations. Figure 16 shows the geographic distribution of the AOD, and a comparison with the observational composite dataset. In general, AOD is over-predicted over the oceans and under-predicted over the land. Hoose et al. (2008) have shown that this over-prediction, particularly over the southern oceans can be corrected with improvements to the water uptake on the aerosols. A new scheme for particle growth due to ambient humidity will be available in subsequent versions of the ECHAM5-HAM and will address this issue.

Figure 17 compares the annual mean wet deposition of sulfate and sodium ions from the National Atmospheric Deposition Program of the United States with the simulations BCS2 and CTL. We assume that sea salt is the only source for sodium ions. For sulfate and sodium ions, both simulations give similar agreement with the observations. A similar agreement with observations was also found for all the remaining simulations that we conducted in this study (not shown). However, a more physically detailed below-cloud scavenging parameterization is desirable in global models, and our results show that the implementation of such a parameterization gives very reasonable results.

\section{Conclusions}

This study has examined the impacts of below-cloud scavenging parameterizations for rain and snow on global and annual mean vertical profiles of aerosol concentrations, and the geographic distribution of aerosol burdens and wet deposition. The aerosol species most sensitive to changes in the below-cloud scavenging parameterizations was sea salt. The global and annual mean sea salt burden was shown to change by near to $15 \%$ depending on the parameterization used. Sea salt and dust mass burdens were found to be sensitive to the below-cloud scavenging coefficients used for the coarse mode scavenging. These coarse mode coefficients were shown to vary over several orders of magnitude depending on whether the rain drops are assumed to be unimodal and 0.4 or $4.0 \mathrm{~mm}$ in diameter, or having an exponential distribution. Thermophoretic effects were shown to produce increases in the global and annual mean below-cloud number removal of Aitken size particles of near to $15 \%$, but very small increases (near 1\%) in the global below-cloud mass scavenging of carbonaceous and sulfate aerosols. Annual and zonal mean nucleation mode number concentrations were enhanced by up to $30 \%$ in the lower troposphere for the more vigorous size-dependent below-cloud scavenging since there was a reduction in the available condensation surface from the accumulation and coarse modes. Between the various below-cloud scavenging parameterizations, the global mean cloud properties did not change significantly since the internally mixed/soluble Aitken and accumulation mode number concentrations were changed by less than $10 \%$.

Future work should be directed towards improving our understanding of the below-cloud scavenging by snow, and developing more physically correct representations of this process in global models. Changes to the parameterization of the below-cloud scavenging by snow was found to change 
the insoluble accumulation and coarse aerosol number concentrations by up to $50 \%$ poleward of $45^{\circ} \mathrm{N}$ and $45^{\circ} \mathrm{S}$. Additionally, in this study we assumed that all of the snow was the same size and shape, which does affect the below-cloud scavenging efficiency and the impact of these factors on a global scale requires further investigation. We also did not implement a prognostic scheme for the treatment of snowfall in the model, which may be even more important than prognostic rain since fall velocities for snow are generally smaller than for rain. Ultimately, more physically based parameterizations of the below-cloud scavenging by both rain and snow in global climate models will improve confidence in our estimates of the direct and indirect radiative forcing of aerosols.

Acknowledgements. The authors thank Jan Kazil, Corinna Hoose, and two anonymous reviewers for their helpful comments and discussions. We are also grateful to the National Science and Engineering Research Council of Canada and Killam Trusts Foundation of Canada for financial support, and to ETH Zurich for computing time.

Edited by: K. Lehtinen

\section{References}

Andronache, C.: Estimated variability of below-cloud aerosol removal by rainfall for observed aerosol size distributions, Atmos. Chem. Phys., 3, 131-143, 2003, http://www.atmos-chem-phys.net/3/131/2003/.

Andronache, C., Groenholm, T., 1. Laasko, Phillips, V., and Venalainen, A.: Scavenging of ultrafine particles by rainfall at a boreal site: observations and model estimations, Atmos. Chem. Phys., 6, 4739-4754, 2006,

http://www.atmos-chem-phys.net/6/4739/2006/.

Beard, K. V.: Terminal velocity and shape of cloud and precipitation drops aloft, J. Atmos. Sci., 33, 851-864, 1976.

Beard, K. V. and Pruppacher, H. R.: A determination of the terminal velocity and drag of small water drops by means of a wind tunnel, J. Atmos. Sci., 26, 1066-1072, 1969.

Cagnazzo, C., Manzini, E., Giorgetta, M. A., Forster, P. M. D. F., and Morcrette, J. J.: Impact of an improved radiation scheme in the MAECHAM5 General Circulation Model, Atmos. Chem. Phys., 7, 2503-2515, 2007, http://www.atmos-chem-phys.net/7/2503/2007/.

Charlson, R. J., Schwartz, S. E., Hales, J. M., Cess, R. D., Coakley, J. A., Hansen, J. E., and Hofmann, D. J.: Climate forcing by anthropogenic aerosols., J. Geophys. Res., 255, 423-430, 1992.

Dentener, F., Kinne, S., Bond, T., Boucher, O., Cofala, J., Generoso, S., Ginoux, P., Gong, S., Hoelzemann, J., Ito, A., Marelli, L., Penner, J. E., Putaud, J.-P., Textor, C., Schulz, M., van der Werf, G. R., and Wilson, J.: Emissions of primary aerosol and precursos gases in the years 2000 and 1750: prescribed data-sets for AeroCom, Atmos. Phys. Chem., 6, 4321-4344, 2006.

Dick, A. L.: A simple model for air/snow fractionation of aerosol components over the Antarctic Peninsula, J. Atmos. Chem., 11, 179-196, 1990.
Feng, J.: A size-resolved model for below-cloud scavenging of aerosols by snowfall, J. Geophys. Res., 114, D08203, doi:10.1029/2008JD011012, 2009.

Ferraro, R., Weng, F., Grody, N., and Basist, A.: An Eight Year (1987-1994) Time Series of Rainfall, CLouds, Water Vapor, Snow-cover, and Sea-ice Derived from SSM/I Measurements, B. Am. Meteorol. Soc., 77, 891-905, 1996.

Garner, F. H. and Lihou, D. A.: DECHEMA Monographien, 55, $155,1965$.

Gong, S. L., Barrie, L. A., and Blanchet, J.-P.: Modeling sea-salt aerosols in the atmosphere: 1. Model development, J. Geophys. Res., 102, 3805-3818, 1997.

Greenfield, S.: Rain scavenging of radioactive particulate matter from the atmosphere., J. Meteor., 14, 115-125, 1957.

Greenwald, T. J., Stephens, G. L., Haar, T. H. V., and Jackson, D. L.: A Physical Retrieval of CLoud Liquid Water Over the Global Oceans Using Special Sensor Microwave/Imager ((SSM/I) Observations, J. Geophys. Res., 98, 18471-18488, 1993.

Gunn, R. and Kinzer, G. D.: The terminal velocity of fall for water droplets in stagnant air, J. Meteor., 6, 243-248, 1949.

Hall, W. D.: A detailed microphysical model within a twodimensional dynamic framework:Model description and preliminary results., J. Atmos. Sci., 37, 2486-2507, 1980.

Han, Q., Rossow, W. B., Chou, J., and Welch, R.: Global variation of column droplet concentration in low-level clouds, Geophys. Res Lett., 25, 1419-1422, 1998.

Henzing, J. S., Olivie, D. J. L., and Velthoven, P. F. J. V.: A parameterization of size resolved below cloud scavenging of aerosols by rain, Atmos. Chem. Phys., 6, 3363-3375, 2006, http://www.atmos-chem-phys.net/6/3363/2006/.

Hoose, C., Lohmann, U., Bennartz, R., Croft, B., and Lesins, G.: Global simulations of aerosol processing in clouds, Atmos. Chem. Phys., 8, 6939-6963, 2008, http://www.atmos-chem-phys.net/8/6939/2008/.

Joss, J. and Waldvogel, A.: Raindrop size distribution and sampling size errors, J. Atmos. Sci., 26, 566-569, 1969.

Jung, C. H. and Lee, K. W.: Filtration of fine particles by multple liquid drop and gas bubble systems, Aeros. Sci. Tech., 29, 389401, 1998.

Kärcher, B. and Lohmann, U.: A parameterization of cirrus cloud formation: Homogeneous freezing of supercooled aerosols, J. Geophys. Res., 107(D2), 4010, doi:10.1029/2001JD000470, 2002.

Kinne, S.: Remote sensing data combinations - superior global maps for aerosol optical depth, in: Satellite Aerosol Remote Sensing Over Land, edited by: Kokhanovsky, A. A. and De Leeuw, G., Springer, 2009.

Klett, J. D. and Davis, M. H.: Theoretical collision efficiencies of cloud droplets at small Reynolds numbers, J. Atmos. Sci., 30, 107-117, 1973.

Lin, C. L. and Lee, S.: Collision efficiency of water drops in the atmosphere., J. Atmos. Sci., 32, 1412-1418, 1975.

Lin, S. J. and Rood, R. B.: Multidimensional flux form semiLagrangian transport, Mon. Weather Rev., 124, 2046-2068, 1996.

Lohmann, U., Stier, P., Hoose, C., Ferrachat, S., Kloster, S., Roeckner, E., and Zhang, J.: Cloud microphysics and aerosol indirect effects in the global climate model ECHAM5-HAM, Atmos. Chem. Phys., 7, 3425-3446, 2007, 
http://www.atmos-chem-phys.net/7/3425/2007/.

Marshall, J. S. and Palmer, W. M.: The distribution of raindrops with size, J. Meteor., 5, 165-166, 1948.

Miller, N. L. and Wang, P. K.: A theoretical deptermination of the collection rates of aerosol particles by falling ice crystal plates and columns, Atmos. Environ., 25A, 2593-2606, 1991.

Mlawer, E. J., Taubman, S. J., Brown, P. D., Iacono, M. J., and Clough, S. A.: Radiative transfer for inhomogeneous atmosphere: RRTM, a validated correlated-k model for the longwave, J. Geophys. Res., 102, 16663-16682, 1997.

Morcrette, J.-J., Clough, S. A., Mlawer, E. J., and Iacono, M. J.: Impact of a validated radiative transfer scheme, RRTM, on the ECMWF model cliamte and 10-day forecasts, ECMWF, Reading, UK, technical memorandum 252 edn., 1998.

Nordeng, T. E.: Extended versions of the convective parameterization scheme ay ECWMF and their impact on the mean and transient activity of the model in the tropics, ECMWF, Reading, UK, technical memorandum edn., 1994.

Posselt, R. and Lohmann, U.: Introduction of prognostic rain in ECHAM5: Design and single column model simulations, Atmos. Phys. Chem., 8, 2949-2963, 2008.

Pruppacher, H. R. and Klett, J. D.: Microphysics of clouds and precipitation., Kluwer Academic Publishers, Dordrect, Boston, London, UK, 1998.

Rasch, P. J., Feitcher, J., Law, J., and et al.: A comparison of scavenging and deposition processes in global models: results from the WCRP Cambridge Workshop of 1995, Tellus, 52B, 10251056, 2000.

Roeckner, E., Baeuml, G., Bonventura, L., Brokopf, R., Esch, M., Giorgetta, M., Hagemann, S., Kirchner, I., Kornblueh, L., Manzini, E., Rhodin, A., Schlese, U., Schilzweida, U., and Tompkins, A.: The atmospheric general circulation model ECHAM5. Part I: Model description, Report 349, Max Planck Institute for Meteorology, Hamburg, Germany, online available at: http://www.mpimet.mpg.de, 2003.

Rossow, W. B. and Schiffer, R. A.: Advances in understanding clouds from ISCCP, B. Am. Meteor. Soc., 80, 2261-2287, 1999.

Schlamp, R. J., Grover, S. N., and Pruppacher, H. R.: A numerical investigation of the effect of electric charges and vertical external electric fields on the collision efficiency of cloud drops., J. Atmos. Sci., 33, 1747-1755, 1976.

Seinfeld, J. H. and Pandis, S. N.: Atmospheric Chemistry and Physics, Wiley, New York, USA, 1998.
Slinn, W. G. N.: Precipitation Scavenging in Atmopsheric Science and Power Production, CH. 11, edited by: Randerson, D., Tech. Inf. Cent., Off. of Sci. and Techn. Inf., Dep. of Energy, Washington DC, USA, 466-532, 1984.

Stier, P., Feichter, J., Kinne, S., Kloster, S., Vignati, E., Wilson, J., Ganzeveld, L., Tegen, I., Werner, M., Balkanski, Y., Schultz, M., Boucher, O., Minikin, A., and Petzold, A.: The aerosolclimate model ECHAM5-HAM, Atmos. Chem. Phys., 5, 11251156, 2005, http://www.atmos-chem-phys.net/5/1125/2005/.

Storelvmo, T., Kristjansson, J.-E., and Lohmann, U.: Aerosol influences on mixed-phase cloud in CAM-Oslo, J. Atmos. Sci., 60, 3214-3230, 2008.

Textor, C., Schulz, M., Guibert, S., Kinne, S., Balkanski, Y., Bauer, S., Berntsen, T., Berglen, T., Boucher, O., Chin, M., Dentener, F., Easter, R., Fillmore, D., Ghan, S., Ginoux, P., Gong, S., Grini, A., Hendricks, J., Horowitz, L., Huang, P., Isaksen, I., Iversen, T., Kloster, S., Koch, D., Kirkevag, A., Kristjansson, J. E., Krol, M., Lauer, A., Lamarque, J., Liu, X., Montanaro, V., Myhre, G., Penner, J., Pitari, G., Reddy, S., Seland, O., Stier, P., Takemura, T., and Tie, X.: Analysis and quantification of the diversities of aerosol life cycles within AeroCom, Atmos. Chem. Phys., 6, 1777-1813, 2006, http://www.atmoschem-phys.net/6/1777/2006/.

Tiedtke, M.: A comprehensive mass flux scheme for cumulus parameterization in large scale model, Mon. Weather Rev., 117, 1779-1800, 1989.

Tost, H., Jockel, P., Kerkweg, A., Sander, R., and Lelieveld, J.: Technical note: A new comprehensive SCAVenging submodel for global atmospheric chemistry models, Atmos. Chem. Phys., 6, 565-574, 2006, http://www.atmos-chemphys.net/6/565/2006/.

Twomey, S.: Aerosol, clouds, and radiation., Atmos. Environ., 25A, 2435-2442, 1991.

Wang, P. K., Grover, S. N., and Pruppacher, H. R.: On the effect of electric charges on the scavenging of aerosol particles by clouds and small raindrops, J. Atmos. Sci., 35, 1735-1743, 1978.

Weng, F. and Grody, N. C.: Retrieval of cloud liquid water using the special sensor microwave imager (SSM/I), J. Geophys. Res., 99, 25535-25551, 1994.

Young, K. C.: Microphysical processes in clouds, Oxford University Press, New York, Oxford, 1993. 